\title{
Mechanical Properties of Recycled Aggregate Concrete Modified by
} Nano-particles

\author{
Chang Gao ${ }^{1}$, Liang Huang ${ }^{*}$, Libo Yan ${ }^{2,3 *}$, Ruoyu Jin ${ }^{4}$, Haoze Chen ${ }^{3}$ \\ ${ }^{1}$ College of Civil Engineering, Hunan University, Changsha 410082, China \\ ${ }^{2}$ Centre for Light and Environmentally-Friendly Structures, Fraunhofer Wilhelm-Klauditz-Institut WKI, \\ Bienroder Weg 54E, Braunschweig 38108, Germany \\ ${ }^{3}$ Department of Organic and Wood-Based Construction Materials, Technische Universität \\ Braunschweig, Hopfengarten 20, 38102 Braunschweig, Germany \\ ${ }^{4}$ School of Environment and Technology, University of Brighton, Cockcroft Build. 616, Brighton, UK \\ *Corresponding authors: Liang Huang. Email: lianghuanghnu@gmail.com \\ Libo Yan. Email: 1.yan@,tu-braunschweig.de
}

\begin{abstract}
In this study, different nano-particles were used to modify recycled aggregates concrete (RAC) containing recycled clay brick aggregates (RCBAs) to improve the RAC properties. Two stages of experimental works were performed. In the first stage, various nano-particle mixtures produced by different mixing methods, i.e. the use of surfactant and ultrasonication, were examined by optical microscope to evaluate the dispersion of the nano-particles in water liquid. The nano-particles modified cement mortar specimens were further evaluated by flexural tensile test to check how these mixing methods affect the properties of the nano-particle modified cement mortar. In the second experimental stage, the effects of four replacement ratios of recycled aggregates, three type of nano-particles, two mixing methods of RAC, additional surfactant and ultrasonication process used in the mix of nano-particle liquid, and the dosages of the nano-particles on the workability, compressive and split tensile properties of the nano-particle modified RAC were investigated.
\end{abstract}

Keywords: Recycled aggregate concrete (RAC), Recycled clay brick aggregate (RCBA), Nano-particles, Mechanical properties, Interfacial Transition Zone (ITZ), Ultrasonication

List of acronyms

\begin{tabular}{|llll|}
\hline$R A C$ & Recycled aggregate concrete & $I T Z$ & Interfacial Transition Zone \\
$R C B A$ & Recycled clay brick aggregate & $N S$ & Nano- $\mathrm{SiO}_{2}$ material \\
$R A S$ & Recycled aggregates & $N C$ & Nano-CaCO \\
$N A C$ & Natural aggregate concrete & $M W C N T S$ & Multi-walled carbon nanotubes \\
$N A S$ & Natural aggregates & $C N T S$ & Carbon nano-tubes \\
$f_{\mathrm{c}}$ & Compressive strength & $M I$ & Mixing method I \\
$f_{\text {st }}$ & Split tensile strength & $M I I$ & Mixing method II \\
$f_{\text {st,code }}$ & Calculated split tensile strength & $C$ & Compressive tests \\
$f_{\text {st }, 150}$ & Tested split tensile strength of cubes & $T$ & Split tensile tests \\
$A$ & Area of split surface & $U V$ & Ultrasonic vibration mix method \\
$D$ & Diameter of cylindrical specimens & $S F C$ & Surfactant process \\
$H$ & Height of cylindrical specimens & $T S M A$ & Two-stage mixing approach \\
\hline
\end{tabular}




\section{Introduction}

With the progress of urbanization, massive quantities of construction and demolition wastes (CDW) are generated which are not only difficult to dispose, but also cause environmental pollution and economic problems [1-4]. It is reported that over 500 million tons of CDW are produced annually in the worldwide [5]. While on the other hand the depletion of huge amounts of natural resources such as the use of natural aggregates in construction also causes burden on environmental issues. Therefore, how to reduce the depletion of natural resources and also how to promote the recycle and reuse of CDW become a worldwide challenge. One coping approach to address both issues is to develop and use recycled aggregates (RAs) originated from CDW to produce recycled aggregate concrete (RAC) for new construction application. In RAC, recycled aggregates (RAs) are typically used to partially or fully replace the natural aggregates (NAs) [6-7]. RAC is considered as an economical and environmentally friendly concrete which can conserve the landfilling space for CDW and reduce the shortage of natural resources [8].

Research on using RAC in new concrete construction has been studied for decades [1]. The major problem of promoting RACs for practice is their inferior properties when comparing with those of NAC, e.g., such as low compressive, tensile and flexural strength, high water absorption and porosity of RAs, large shrinkage of the RAC [9-11]. Due to those weaknesses, the dosage of RAs used for replacing NAs for RAC has been limited, e.g., normally $20 \%-35 \%$ or even lower replacement ratio of NAs was used in structural application [12]. In most European and Asian countries, the waste clay brick aggregates occupy around $45 \% \sim 50 \%$ of RAs since most existing constructions and buildings were made of bricks and masonries [13-15]. RAs generally consist of $45 \% \sim 50 \%$ of recycled clay brick aggregates (RCBAs) and 55\% 50\% of recycled concrete or bubble aggregates, and some waste glass or wood chips. It is both technically and economically impossible to sort out pure recycled concrete aggregates from the mixture of RAs $[9,15]$. For RAs with RCBAs obtained from old masonry and brick wastes, normally they present higher water absorption and lower crushing indices than those of RAs sorted from old concrete waste, as the original strength of bricks and masonry structures are lower than that of concrete [16]. Research indicates that the inferior performance of RACs is attributed to the waste mortar attached to the surface of the RAs which was defined with porous, micro cracks and drawbacks [17]. Previous studies have confirmed that the mechanical properties of concrete are highly dependent on the properties of the interfacial transition zone (ITZ) between new cement mortar and aggregates [18-24]. More ITZs exist in the RAC which is another reason for the inferior quality of RAC, and the relative quality of the old ITZ and the new ITZs in RAC affect the strength of the RAC significantly [18]. Actually, three ITZs exist in the RAC: ITZ-1 is between the old attached mortar and the natural aggregates, ITZ-2 is between the natural aggregates and the new cement mortar, and ITZ-3 is between the old and new cement mortar as seen in Fig. 1(b) [20]. In comparison only ITZ-2 exists in NAC as in Fig 1(c). 


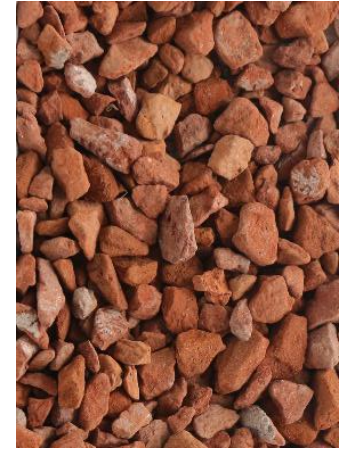

(a)

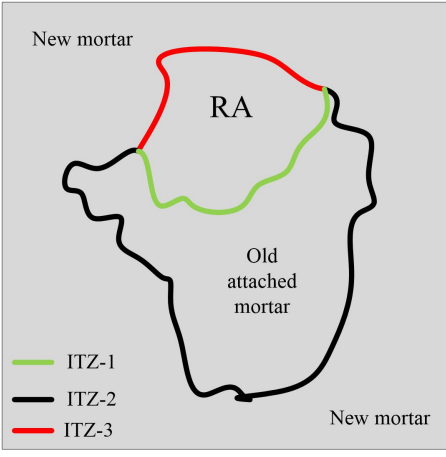

(b)

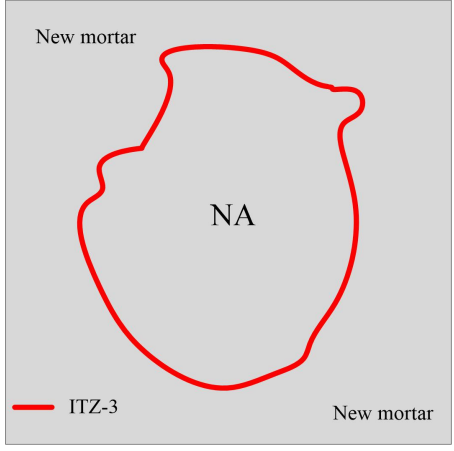

(c)

Fig. 1 a) RCBAs, b) ITZs of RAC, (c) ITZ of NAC

In the past decades, researchers have tried various reinforcing and optimizing approaches aiming to improve the performance of RAs and their resulting RACs. For examples, attempts have been carried out to optimize the microstructures of the RAs and in turn to improve the resulting RAC properties by using fly ash, silica fume with pozzolanic reaction and filling ability to produce more solid micro-structures of the RAs and stronger ITZs in the RAC [25-28]. Recently, the application of nano-technology has gained the momentum in different fields [30-31]. Nano-materials have been used in concrete to achieve superior mechanical properties and durability of conventional NAC [32-35]. Nano-materials are defined as nano-scale size particles with the diameter of less than $100 \mathrm{~nm}$, such as nano- $\mathrm{SiO}_{2}$, nano- $\mathrm{CaCO}_{3}$, nano- $\mathrm{TiO}_{2}$, and carbon nanotubes [33-35]. Proper nano-particles can enhance the strength and durability of concrete, reduce the permeability of concrete by coating the surface of the aggregates, filling the micropores to decrease concrete porosity, accelerating the hydration reaction of cement, and strengthening the bonds of interfacial ITZs between the aggregates and the cement paste [35]. The potential of nano-technology in enhancing the performance of concrete and developing novel, sustainable, advanced cement composites with unique mechanical, thermal, and electrical properties is promising [35]. For example, nano- $\mathrm{SiO}_{2}$ (NS) particle as the most popular nanomaterial mixture in concrete modification provided an excellent performance in improving the mechanical properties and durability of NAC [20, 38-40]. Studies have shown that the addition of NS in fresh concrete resulted in $21.6 \%$ increase of compressive strength [38], and changed the microstructures by filling the voids of each content of concrete mixture physically and helping form the C-S-H crystal nucleus of cement paste, which in turn changed the physical properties and durability of concrete mixture [36-38]. The nano- $\mathrm{CaCO}_{3}$ (NC) particle was primarily used as filler to reduce the porosity of aggregates in its powder form. Recent studies have shown that the NC could accelerate the hydration rate of cement and improve the early-age properties of NAC [41]. Studies have also shown that carbon nano-tubes (CNTs) could improve the mechanical properties, reduce the initial shrinkage, improve durability and modify the microstructures of cementitious matrices [42-44]. An appropriate incorporation of surface modified CNTs with a mass content of $0.4 \% \sim 0.5 \%$ resulted in $19 \% \sim 25 \%$ increase in compressive and flexural strength of the cement pastes [45] and resulted in 35\% lower shrinkage of the cement matrix [46]. Hawreen et al. [47] investigated the effects of dosages of CNTs with incorporation of $0.05 \sim 0.1 \%$ on the mechanical and shrinkage behavior, and found respective $33 \%$ and $65 \%$ 
increase in flexural strength of mortar with $0.05 \%$ and $0.1 \%$ CNTs. In contrast, the insufficient dispersion of CNTs could lead to inferior performance than that of common cement mixtures [48]. A major disadvantage of using nano-sized materials as admixture in concrete is that the nanoscale materials tend to form agglomerates during wetting and mixing due to the considerable Van der Waals' force among the molecules [44]. Unless the individual particles are well dispersed, agglomeration will reduce the exposed particle surface area and lead to poor micro-structures of the concrete mix and in turn even reduce the properties of the concrete mix [49-51]. It is crucial that the mixing water, cement and nano-admixtures are evenly dispersed and distributed down to a fine scale, otherwise the insufficient dispersing and de-agglomeration could result in inferior concrete properties, e.g., partial stress concentration and pre-existing micro-cracks of concrete structure, and lower strength [20]. Ultra-sonication is proved to be an effective approach for mixing, dispersing and de-agglomeration of nano-particles or aggregates [52]. The ultrasonication, with its high frequency of vibration, could accelerate the dispersion of nano-particles and other mixtures in the concrete [53].

In view of the characteristics of nano-particles and their superior performance in promoting the properties of cement-based materials and NAC, it is worth investigating the feasibility of applying nano-materials to improve the performance of RAC with RCBAs. This study therefore aims to investigate the mechanical properties of RACs containing RCBA modified by various nano-particles. To improve the dispersion of nano-particles in the RAC, different mixing methods, e.g. surfactant and ultrasonication, were further used to process the nano-particle liquids. Specifically, the objectives of the current study include:

1) to investigate the effect of ultrasonication and surfactant processes on the dispersion of nano-materials which is examined by microscope observation and evaluated by the flexural tensile test of the nano-particles modified cement mortar specimens;

2) to compare the compressive and tensile properties of nano-particles (i.e., nano- $\mathrm{SiO}_{2}$, nano- $\mathrm{CaCO}_{3}$, and carbon nanotubes) modified fresh RAC with RCBAs and NAC, and the tested variables included the curing ages of the RACs, the replacement ratios of RAs for RAC, dosages and types of nano-particles, and two kinds of two-stage mixing methods of RAC mixtures;

3) to compare the experimental split tensile results of nano-particles modified RAC with the predictions based on the different equations listed in concrete design standards, i.e., ACI 318 [56], GB 10010 [57], CEB [58], EHE [59], NBR 6118 [60].

\section{Experimental program}

\subsection{Raw materials}

Recycled coarse aggregates (RCAs) used in this study were obtained from construction and demolition wastes which were crushed and screened by Jinke Resource Recycling Co. in China. The RAs consisted of 55\% recycled clay brick aggregates (RCBAs) and 45\% recycled concrete and mortar aggregates by mass (Fig 2(a)). The natural coarse aggregates (NCAs) were natural gravels and the natural fine aggregates (NFA) were natural river sands with a fineness modulus of 2.57. The physical properties and the sizes of the RAs and NAs are listed in Table 1 and Fig 2, respectively. The nano- $\mathrm{SiO}_{2}(\mathrm{NS})$ and nano- $\mathrm{CaCO}_{3}(\mathrm{NC})$ were purchased from Hangzhou Wanjing New material CO., LTD., China, and the physical properties of NS 
and NC are listed in Table 2 and Table 3, respectively. The type of the carbon nanotubes used in the tests was the multi-walled carbon nanotubes (MWCNTs), named L-MWCNT-2040 and the physical properties of MWCNTs are listed in Table 4.

Table 1 Physical properties of RCA and NCA

\begin{tabular}{ccccccc}
\hline Types & $\begin{array}{c}\text { Particle size } \\
(\mathrm{mm})\end{array}$ & $\begin{array}{c}\text { Density } \\
\left(\mathrm{kg} / \mathrm{m}^{3}\right)\end{array}$ & $\begin{array}{c}\text { Porosity } \\
(\%)\end{array}$ & $\begin{array}{c}\text { Water absorption } \\
(\%)\end{array}$ & $\begin{array}{c}\text { Moisture content } \\
(\%)\end{array}$ & $\begin{array}{c}\text { Crushing index } \\
(\%)\end{array}$ \\
\hline RCA & $5 \sim 10$ & 1140 & 10 & 14.8 & 6.5 & 17.3 \\
NCA & $5 \sim 10$ & 1620 & 6 & 1.7 & 0.3 & 10.7 \\
\hline
\end{tabular}

7

(16)

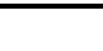

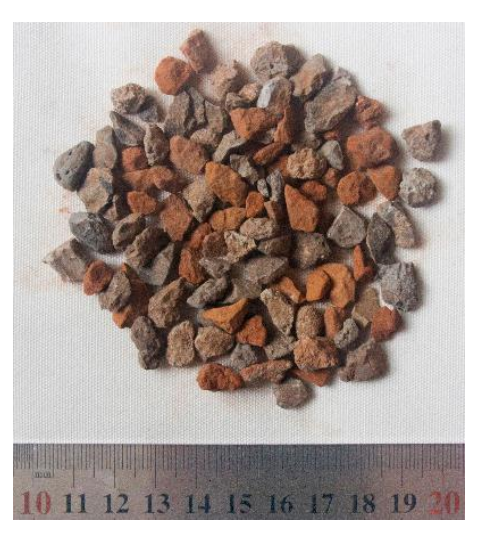

(a)

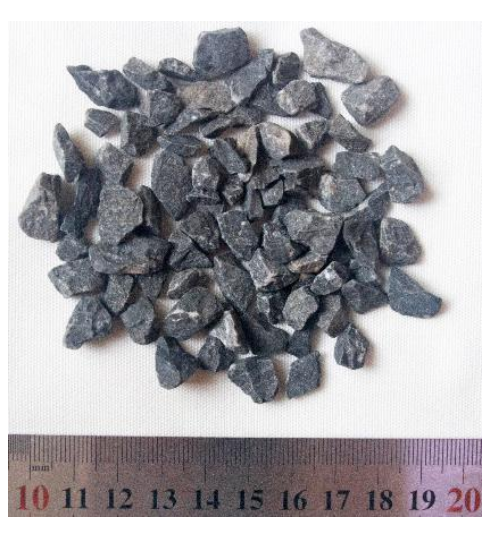

(b)

Fig. 2 Coarse aggregates a) RAs and b) NAs

Table 2 Physical properties of nano- $\mathrm{SiO}_{2}$

\begin{tabular}{ccccccc}
\hline & Appearance & Density $\left(\mathrm{g} / \mathrm{cm}^{3}\right)$ & Size $(\mathrm{nm})$ & $\mathrm{pH}$ & Purity & Price $/ \mathrm{kg}$ \\
\hline NS & White flocculent powder & $1.1 \sim 1.2$ & $15 \sim 30$ & $5 \sim 7$ & $\geq 99.5 \%$ & $\$ 29$ \\
\hline
\end{tabular}

Table 3 Physical properties of nano- $\mathrm{CaCO}_{3}$

\begin{tabular}{|c|c|c|c|c|c|c|c|c|}
\hline & Appearance & $\begin{array}{l}\text { Density } \\
\left(\mathrm{g} / \mathrm{cm}^{3}\right)\end{array}$ & Size (nm) & $\begin{array}{c}\text { Particle } \\
\text { shape }\end{array}$ & $\mathrm{PH}$ & Purity & Character & Price $/ \mathrm{kg}$ \\
\hline $\mathrm{NC}$ & White powder & $2.5 \sim 2.6$ & $15 \sim 40$ & Cube & $8 \sim 9$ & $\geq 98.5 \%$ & Hydrophilic & $\$ 33$ \\
\hline
\end{tabular}

Table 4 Physical properties of MWCNTs

\begin{tabular}{ccccccc}
\hline & $\begin{array}{c}\text { Outer Diameter } \\
(\mathrm{nm})\end{array}$ & Length $(\mu \mathrm{m})$ & Purity $(\%)$ & $\begin{array}{c}\text { Density } \\
\left(\mathrm{g} / \mathrm{cm}^{3}\right)\end{array}$ & $\begin{array}{c}\text { Specific Surface } \\
\text { Area }\left(\mathrm{m}^{2} / \mathrm{g}\right)\end{array}$ & Price/kg \\
\hline L-MWCNT-2040 & $20-40$ & $5-15$ & $>97$ & 0.22 & $90-120$ & $\$ 295$ \\
\hline
\end{tabular}

Previous studies revealed that an upper limit dosage of nanoparticles existed for cement-based materials [26]. Excessive usage of nano-particles beyond the upper limit could cause a negative effect on the mechanical properties of concrete but also raise the material cost. The recommended dosages of NS and NC were $1 \mathrm{wt} . \%$ and $2 \mathrm{wt} . \%$ of the cement to have an optimized enhancement in the compressive or flexural properties [33, 38]. The dosage of 
MWCNT used for cement was 0.1 wt.\% of cement as suggested by Hawreen et al. [47]. As nanoparticles are hard to disperse in the cement, thus, in current study, surfactant and ultrasonication were further applied to process the nano-particle liquid.

\subsection{Test matrix}

A total of 64 categories of RAC cubic specimens were prepared and tested to obtain the mechanical properties of nano-particle modified RACs, i.e., 48 categories of cubic specimens were tested under the compression load (i.e., 16 categories of various RACs at 3d-, 7d- and $28 \mathrm{~d}$-compressive tests, respectively) and 16 categories of cubic specimens were tested under the split tensile load at 28-day. Each category of RAC included 6 identical cubic specimens with a size of $150 \times 150 \times 150 \mathrm{~mm}^{3}$. In total, $384 \mathrm{RAC}$ cubes were constructed to evaluate the compressive and split tensile properties of RACs. The test variables included the replacement ratios of the RAs (i.e., $0 \mathrm{wt} . \%, 50 \mathrm{wt} . \%, 70 \mathrm{wt} . \%$ and $100 \mathrm{wt} . \%$ ), the types of nano-particles (i.e., NS, NC and MWCNT), the dosage of nano-particles (i.e., 1 wt. $\%$ and 2 wt. $\%$ of NS, 1 wt. $\%$ and 2 wt. $\%$ of NC, 0.1 wt.\% of MWCNT), two different two-stage mixing approaches for the fresh concrete mixtures (mixing methods I and II, details of these two mixing methods are given in Section 2.3), the application of surfactant (denoted as SFC) and the ultrasonication processes (denoted as UV, details are given in Section 2.3) for dispersing the nanoparticles. The details of all the specimens are listed in Table 5, where RAC-0\% (i.e., NAC) represents natural aggregate concrete specimens mixed without RAs; RAC followed by a percentage represented the RAC with different replacement ratios of RAs for plain RAC specimens; For nano-particles modified RAC specimens, the front letters "NS", "NC" and "MWCNT" represent the types of RAC specimens modified by different nanoparticles; "MI" or "MII" represents the concrete mixing methods as mixing method I and mixing method II which are explained in the following Section 2.3; the numbers "1" and "2" denote the weight ratios of NS and NC to cement, the number " 0.1 " denotes the weight ratios of MWCNT to cement; the last percentages stand for the replacement ratios of RAs; UV means the specimens of NS or MWCNT-modified RAC mixed by using the ultrasonic vibration method and the SFC was used in the production of nanoparticles liquid for all the nanoparticles-modified RAC specimens; the last column means which form of the tests was conducted on each kind of specimens, the abbreviation " $\mathrm{C}$ " means the compressive tests and the abbreviation " $\mathrm{T}$ " means the split tensile tests, and the curing ages of specimens were expressed as 3d-, 7d- and 28d- in front of the abbreviations. For examples, RAC-50\% indicates the RAC specimens without incorporation of nanoparticles and with $50 \%$ replacement ratio of RAs accounting for the coarse aggregates, NS-MII-1-100\% indicates the RAC-RCBA specimens incorporating $1 \mathrm{wt} . \% \mathrm{NS}$, with $100 \%$ replacement ratio of RAs and the second mixing method, NS-MII-1-70\%-UV indicates the RAC-RCBA specimens with $70 \%$ replacement ratio of RAs incorporating $1 \mathrm{wt} . \%$ NS liquid processed with both ultrasonication and surfactant, and the second mixing method of RAC.

Table 5. Details of specimens in compressive tests and split tensile tests

\begin{tabular}{ccccccc}
\hline & Particle & Particle & Replacement \\
No. & Specimen & dosage of & ratio of RAs \\
& & cement & $(r)$ & $\begin{array}{c}\text { Mixing } \\
\text { method }\end{array}$ & $\begin{array}{c}\text { Ultrasonic } \\
\text { vibration }\end{array}$ & $\begin{array}{c}\text { Test and age } \\
\text { of specimens }\end{array}$ \\
\hline
\end{tabular}




\begin{tabular}{|c|c|c|c|c|c|c|c|}
\hline & & & $\begin{array}{c}\text { by } \\
\text { weight }\end{array}$ & & & & \\
\hline 1 & RAC- $0 \%$ (NAC) & & & $0 \%$ & & & $\begin{array}{l}3 \mathrm{~d}-, 7 \mathrm{~d}-\text { and } \\
28 \mathrm{~d}-\mathrm{C} / 28 \mathrm{~d}-\mathrm{T}\end{array}$ \\
\hline 2 & RAC- $50 \%$ & & & $50 \%$ & & & $\begin{array}{l}3 \mathrm{~d}-, 7 \mathrm{~d}-\text { and } \\
28 \mathrm{~d}-\mathrm{C} / 28 \mathrm{~d}-\mathrm{T}\end{array}$ \\
\hline 3 & RAC-70\% & & & $70 \%$ & & & $\begin{array}{l}3 \mathrm{~d}-, 7 \mathrm{~d}-\text { and } \\
28 \mathrm{~d}-\mathrm{C} / 28 \mathrm{~d}-\mathrm{T}\end{array}$ \\
\hline 4 & RAC- $100 \%$ & & & $100 \%$ & & & $\begin{array}{l}3 \mathrm{~d}-, 7 \mathrm{~d}-\text { and } \\
28 \mathrm{~d}-\mathrm{C} / 28 \mathrm{~d}-\mathrm{T}\end{array}$ \\
\hline 5 & NS-MII-1- $0 \%$ & NS & $1 \%$ & $0 \%$ & MII & & $\begin{array}{l}3 \mathrm{~d}-, 7 \mathrm{~d}-\text { and } \\
28 \mathrm{~d}-\mathrm{C} / 28 \mathrm{~d}-\mathrm{T}\end{array}$ \\
\hline 6 & NS-MII-1-50\% & NS & $1 \%$ & $50 \%$ & MII & & $\begin{array}{l}3 \mathrm{~d}-, 7 \mathrm{~d}-\text { and } \\
28 \mathrm{~d}-\mathrm{C} / 28 \mathrm{~d}-\mathrm{T}\end{array}$ \\
\hline 7 & NS-MII-1-70\% & NS & $1 \%$ & $70 \%$ & MII & & $\begin{array}{l}3 \mathrm{~d}-, 7 \mathrm{~d}-\text { and } \\
28 \mathrm{~d}-\mathrm{C} / 28 \mathrm{~d}-\mathrm{T}\end{array}$ \\
\hline 8 & NS-MII-1-100\% & NS & $1 \%$ & $100 \%$ & MII & & $\begin{array}{l}3 \mathrm{~d}-, 7 \mathrm{~d}-\text { and } \\
28 \mathrm{~d}-\mathrm{C} / 28 \mathrm{~d}-\mathrm{T}\end{array}$ \\
\hline 9 & NS-MII-2-70\% & NS & $2 \%$ & $70 \%$ & MII & & $\begin{array}{l}3 \mathrm{~d}-, 7 \mathrm{~d}-\text { and } \\
28 \mathrm{~d}-\mathrm{C} / 28 \mathrm{~d}-\mathrm{T}\end{array}$ \\
\hline 10 & NC-MII-2-70\% & $\mathrm{NC}$ & $2 \%$ & $70 \%$ & MII & & $\begin{array}{l}3 \mathrm{~d}-, 7 \mathrm{~d}-\text { and } \\
28 \mathrm{~d}-\mathrm{C} / 28 \mathrm{~d}-\mathrm{T}\end{array}$ \\
\hline 11 & NC-MII-1-70\% & $\mathrm{NC}$ & $1 \%$ & $70 \%$ & MII & & $\begin{array}{l}3 \mathrm{~d}-, 7 \mathrm{~d}-\text { and } \\
28 \mathrm{~d}-\mathrm{C} / 28 \mathrm{~d}-\mathrm{T}\end{array}$ \\
\hline 12 & NS-MI-1-70\% & NS & $1 \%$ & $70 \%$ & MI & & $\begin{array}{l}3 \mathrm{~d}-, 7 \mathrm{~d}-\text { and } \\
28 \mathrm{~d}-\mathrm{C} / 28 \mathrm{~d}-\mathrm{T}\end{array}$ \\
\hline 13 & NC-MI-1-70\% & $\mathrm{NC}$ & $1 \%$ & $70 \%$ & MI & & $\begin{array}{l}3 \mathrm{~d}-, 7 \mathrm{~d}-\text { and } \\
28 \mathrm{~d}-\mathrm{C} / 28 \mathrm{~d}-\mathrm{T}\end{array}$ \\
\hline 14 & NS-MII-1-70\%-UV & NS & $1 \%$ & $70 \%$ & MII & UV & $\begin{array}{l}3 \mathrm{~d}-, 7 \mathrm{~d}-\text { and } \\
28 \mathrm{~d}-\mathrm{C} / 28 \mathrm{~d}-\mathrm{T}\end{array}$ \\
\hline 15 & MWCNT-0.1-70\% & MWCNT & $0.1 \%$ & $70 \%$ & MII & & $\begin{array}{l}3 \mathrm{~d}-, 7 \mathrm{~d}-\text { and } \\
28 \mathrm{~d}-\mathrm{C} / 28 \mathrm{~d}-\mathrm{T}\end{array}$ \\
\hline 16 & MWCNT-0.1-70\%-UV & MWCNT & $0.1 \%$ & $70 \%$ & MII & UV & $\begin{array}{l}3 \mathrm{~d}-, 7 \mathrm{~d}-\text { and } \\
28 \mathrm{~d}-\mathrm{C} / 28 \mathrm{~d}-\mathrm{T}\end{array}$ \\
\hline
\end{tabular}

Table 6 lists the details of the mix proportions of the concrete batches containing different replacement ratios of RAs and the weights of the nano-particles. The water-cement ratios of all specimens were constant as 0.4 considering the water absorption ratio of the RCAs, based on the previous studies by the authors $[9,10]$. In Table $6, r$ indicates the replacement ratios of RCAs and the gross weight per cubic meters of coarse aggregates. The RAC specimens modified with $1 \mathrm{wt} . \%$ and $2 \mathrm{wt} . \%$ of NS, NC and $0.1 \mathrm{wt} . \%$ of MWCNT are used as the mix proportion in the batches of NS-1 and NS-2, NC-1 and NC-2, MWCNT-0.1, respectively. 


\begin{tabular}{cccccccccc}
\hline Mixture & $\begin{array}{c}\text { Cement } \\
\left(\mathrm{kg} / \mathrm{m}^{3}\right)\end{array}$ & $\begin{array}{c}\text { NCA } \\
\left(\mathrm{kg} / \mathrm{m}^{3}\right)\end{array}$ & $\begin{array}{c}\text { RCA } \\
\left(\mathrm{kg} / \mathrm{m}^{3}\right)\end{array}$ & $\begin{array}{c}\text { NFA } \\
\left(\mathrm{kg} / \mathrm{m}^{3}\right)\end{array}$ & $\begin{array}{c}\text { NS } \\
\left(\mathrm{kg} / \mathrm{m}^{3}\right)\end{array}$ & $\begin{array}{c}\text { NC } \\
\left(\mathrm{kg} / \mathrm{m}^{3}\right)\end{array}$ & $\begin{array}{c}\text { MWCNT } \\
\left(\mathrm{kg} / \mathrm{m}^{3}\right)\end{array}$ & $\begin{array}{c}\text { Water } \\
\left(\mathrm{kg} / \mathrm{m}^{3}\right)\end{array}$ & $\begin{array}{c}r \\
(\%)\end{array}$ \\
\hline NAC & 600.9 & 1041.4 & - & 520.2 & & & & 237.5 & 0 \\
RAC-50\% & 600.9 & 520.7 & 520.7 & 520.2 & & & & 237.5 & 50 \\
RAC-70\% & 600.9 & 312.4 & 729.0 & 520.2 & & & 237.5 & 70 \\
RAC-100\% & 600.9 & - & 1041.4 & 520.2 & & & & 237.5 & 100 \\
NS-1 & 600.9 & 312.4 & 729.0 & 520.2 & 6.0 & & & 237.5 & 70 \\
NC-1 & 600.9 & 312.4 & 729.0 & 520.2 & & 6.0 & & 237.5 & 70 \\
NS-2 & 600.9 & 312.4 & 729.0 & 520.2 & 12.0 & & & 237.5 & 70 \\
NC-2 & 600.9 & 312.4 & 729.0 & 520.2 & & 12.0 & & 237.5 & 70 \\
MWCNT-0.1 & 600.9 & 312.4 & 729.0 & 520.2 & & & 0.6 & 237.5 & 70 \\
\hline
\end{tabular}

In the table, NFA denotes natural fine aggregates

\subsection{Specimen casting and curing}

To improve the properties of RAC modified by nano-particles, researchers recommended the two-stage mixing approach (TSMA) to improve the strength and durability [21]. Quantitative studies revealed that the ITZs of concrete were strengthened through TSMA based on the images of Scanning Electron Microscopy (SEM). Besides, because the poor solubility of nano-particles and the strong Van der Waals forces among MWCNTs, the nanoparticles without pre-dispersion tended to agglomerate [44]. Previous study indicated that the use of surfactant as one alternative method to disperse nano-particles and prevent them from agglomeration effectively [35-37]. The surfactant is one kind of stabilizer which consists of hydrophilic group and lipophilic group. The surfactant could efficiently attract and wrap outside the nanoparticles into colloform due to the excellent absorbability. The formed colloforms wear the same charge which could avoid the agglomeration of the nanoparticle and help stabilize the nanoparticles. Thus, the surfactant of Gum Arabic (GA) was used to promote the dispersion of nano-particles in this study. The weight ratio of all the three types of nano-particles and the GA was 1:6 [37]. The GA was firstly diluted with one tenth of the concrete mixing water and the nano-particles were added into the diluent and mixed with 145 times of rotation per minute by a mixer for one min.

Thus, the mixture of RAC incorporating nano-particles in this study was achieved by two different TSMAs as demonstrated in Fig.3 based on the research by Li [21]. For the first mixing method, namely MI, the nano-particles were immersed into the SFC diluent and artificially stirred gently in a beaker for 1 min to achieve a uniform dispersion which was macroscopically homogeneous without visible agglomeration and stratification. They were then added into RAs with the other half of the water and further mixed for another one min. Finally, cement, sand and the rest of mixing water were poured into the mixture and mixed for another $1.5 \mathrm{~min}$. In the second method, namely MII, the nano-particles were also premixed with the surfactant diluent for $1 \mathrm{~min}$. The cement, sand and RAs were firstly mixed for 0.5 min, then all the water was poured in the mixture and mixed for another $0.5 \mathrm{~min}$. Finally, the nano-particles admixture was added into the concrete mixture and mixed for $1.5 \mathrm{~min}$.

For MWCNT or NS-modified RAC, the alternative ultrasonication method was used to compare with the traditional hand-up stirring method, since it is well known that both the ultrasonic energy could achieve an effective dispersion of nano-particles in water [59]. 
Ultrasonication transforms line voltage into mechanical vibrations and these mechanical vibrations could be transferred into the liquid by creating pressure waves. This action causes the formation and violent collapse of microscopic bubbles and creates millions of shock waves increasing the temperature of the liquid mixtures [21]. Although the amount of energy released by each individual bubble is very small, the cumulative effect could cause extremely high levels of energy to be released and lead to sufficient dispersion of nanoparticles. UV was used during the fabrication of nano-particle liquid admixtures and vibrated for 10 min before the well-dispersed nano-particle admixtures were added into the mixture of concrete [59]. After proper mixing, the fresh concrete was poured into the specified moulds and kept for 24 hours under plastic sheet for maintaining moisture. Then the specimens were demoulded and cured in the standard concrete curing room for 3 days, 7 days and 28 days, respectively for different tests.

\begin{tabular}{|c|c|c|}
\hline \multirow{3}{*}{$\begin{array}{l}\text { Nanoparticles } \\
\text { Water } \\
\text { Surfactant(UV) }\end{array}$} & $\begin{array}{c}\text { RAs } \\
\text { Half mixing water }\end{array}$ & $\begin{array}{c}\text { Cement } \\
\text { Sand }\end{array}$ \\
\hline & \multicolumn{2}{|c|}{ Rest of mixing water } \\
\hline & & 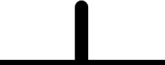 \\
\hline
\end{tabular}

(a) The first TSMA (MI)

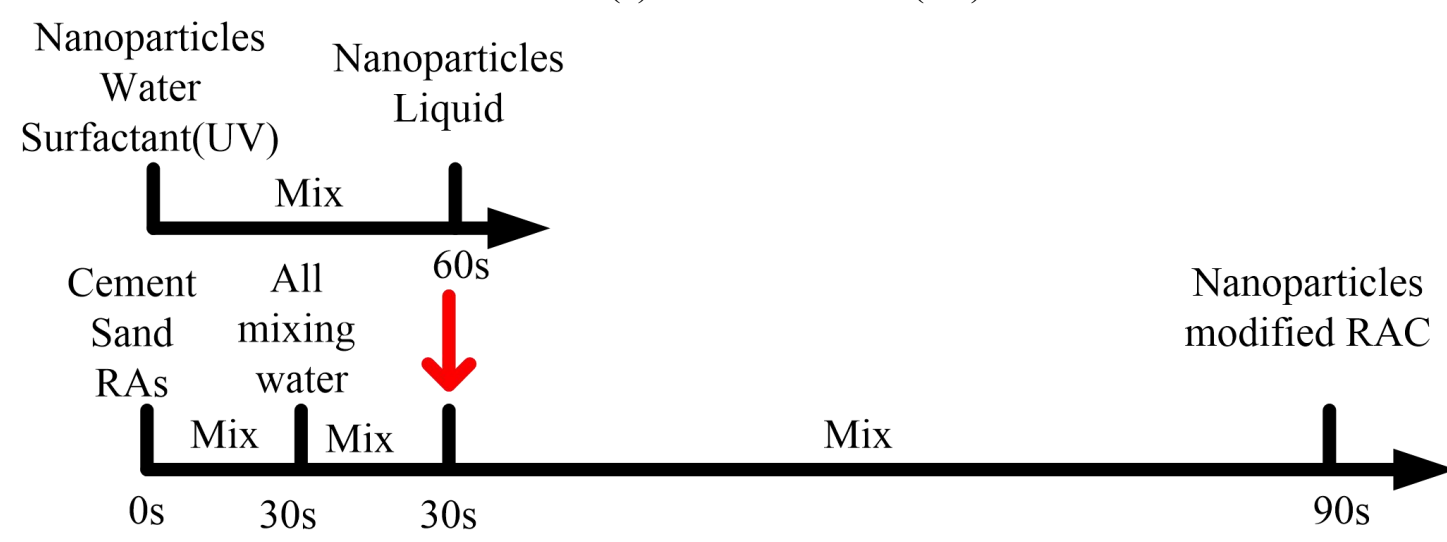

(b) The second TSMA (MII)

Fig.3 Mixing methods [21]

\subsection{Test setup}

The compressive and split tensile tests were carried out using a high-stiffness servo-hydraulic compressional testing machine with a capacity of $20,000 \mathrm{kN}$ as illustrated in Fig. 4(a). Two steel plates were used to balance the pressure. The load control method was adopted with the loading speed of $0.5 \mathrm{MPa} / \mathrm{s}$. The split tensile tests using the prefabricated molds are shown in Fig. 4(b). The molds for splitting tensile tests could better create a pure split tensile loading condition for cubic specimens. 

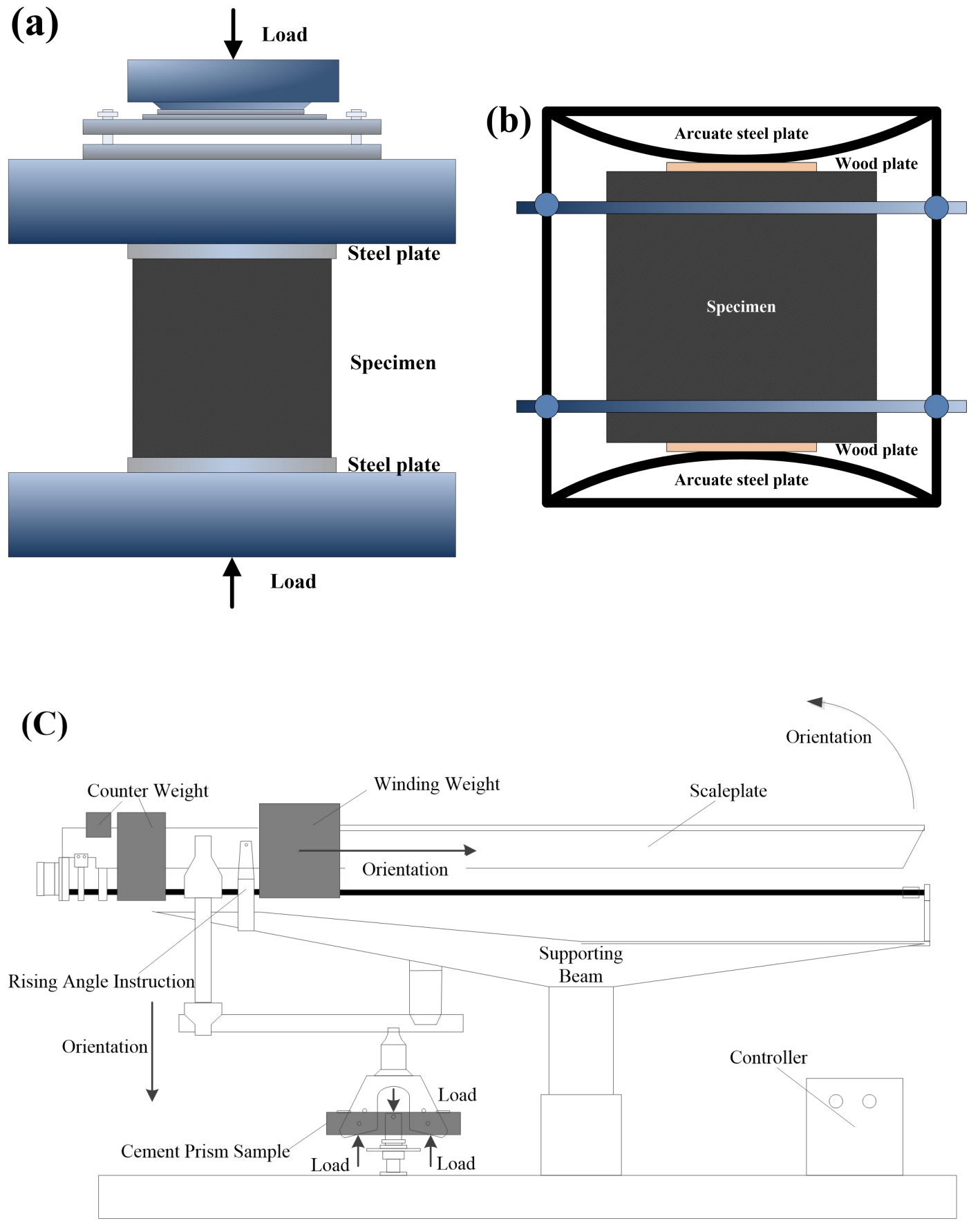

Fig. 4 Test setups: (a) compressive testing, (b) split tensile test, (3) schematic view of standard cement mortar flexural tensile test

\section{Process of nanoparticles and experimental setup}

\subsection{Microscope observation}

The major challenge associated with the incorporation of nano-particles in cement-based materials is how to disperse them evenly in the matrix. In this section, the dispersing efficiency of ultrasonication and surfactant processing methods on MWCNT and NS liquids were evaluated, and the samples were defined as the artificially mixed MWCNT/NS liquid 
without any process, MWCNT/NS incorporating surfactant liquid and MWCNT/NS liquid with process of UV. It should be pointed out that the trial tests of NC liquid have not considered here due to the similar dispersed mechanism to NS [35]. For plain MWCNT/NS liquid which acted as the control group, the MWCNT/NS nano-particles were mixed with some pure water and manually stirred for $10 \mathrm{~min}$. For MWCNT/NS incorporating surfactant liquid, the surfactant was initially diluted with same amount of water as the control group, then the MWCNT/NS nano-particles were mixed with the dilution and manually stirred for 10 min. For MWCNT/NS liquid with process of UV, the MWCNT/NS nano-particles were mixed with same amount of water as the control group and the ultrasonic processor with a cylindrical top was operated into the mixture for $10 \mathrm{~min}$.

The NS and MWCNT liquid solutions with and without surfactant and ultrasonic process were tested and observed using optical microscope. As shown in Fig.5, the MWCNT liquid mixture without surfactant or ultrasonication tended to stick together indicating a poor dispersion of the nano-particles. In comparison, for MWCNT with surfactant (Fig 5(b)) or ultrasonication (Fig 5(c)), the dispersion of MWCNT tended to be uniform. For NS liquid mixture shown in Fig. 6, the NS liquid showed somehow a better dispersion than the plain MWCNT liquid, while for NS liquid with SFC or UV process presented more uniform dispersion. In conclusion, the SFC or UV process were necessary for fabrication of MWCNT liquid, and the SFC or UV process could result in NS liquid with much better dispersion.

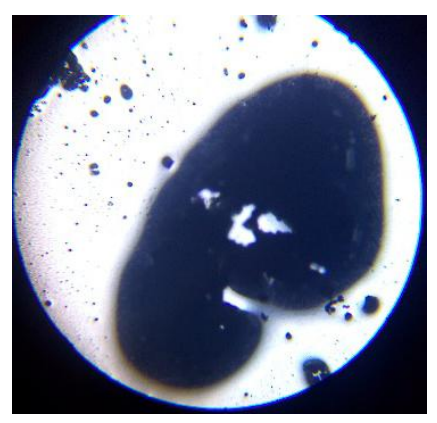

(a) MWCNT liquid

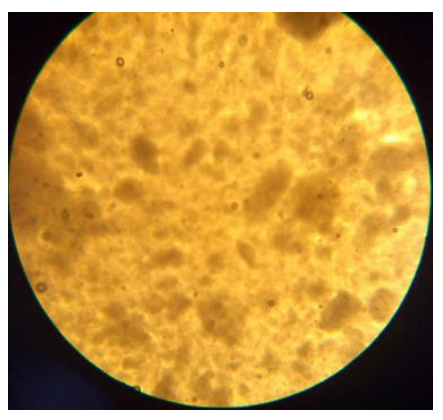

(b) MWCNT liquid with surfactant

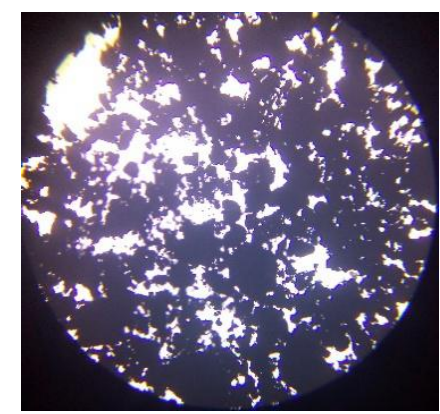

(c) MWCNT liquid with UV Fig.5 Micrographs of MWCNT liquids with different treatment

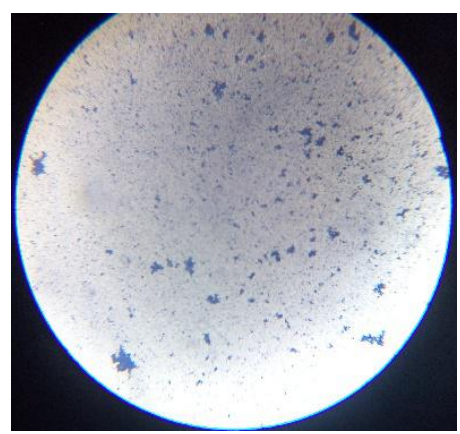

(a) NS liquid

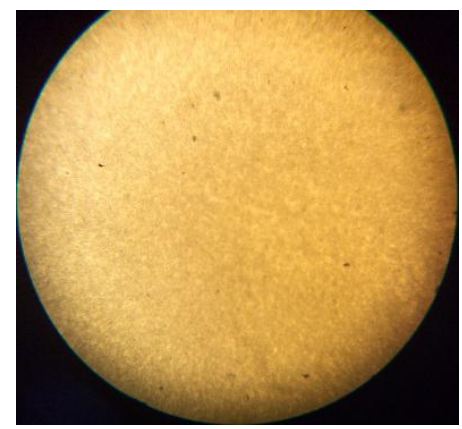

(b) NS liquid with surfactant

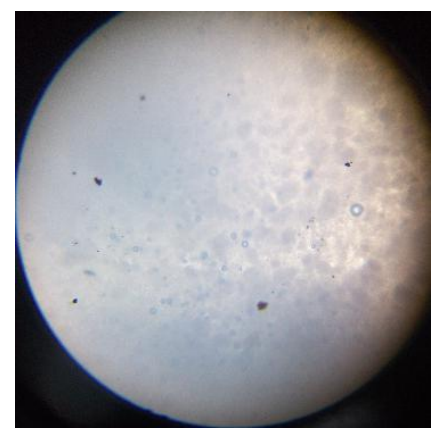

(c) NS liquid with UV

Fig. 6 Micrographs of NS liquids with different treatment

\subsection{Mechanical tests and results}

Nano-particles modified cement mortar samples with or without surfactant or ultrasonication process were tested to investigate the effect of using these two different additional processes on the compressive strength and flexural tensile strength of these nano-particle modified 
cement mortars at $3 \mathrm{~d}, 7 \mathrm{~d}$ and $28 \mathrm{~d}$. The cement mortar samples with a size of $40 \times 40 \times 160$ $\mathrm{mm}^{3}$ were prepared for the flexural tensile test using a standard cement mortar flexural tensile testing machine as illustrated in Fig.4(c) and samples with size of $70.7 \times 70.7 \times 70.7 \mathrm{~mm}^{3}$ were conducted for compression tests. Six categories of cement mortar samples were considered as untreated cement mortar, one NS liquid treated with surfactant alone, one NS liquid treated with ultrasonication process alone, one MWCNT liquid treated with surfactant alone, one MWCNT liquid with ultrasonication process alone, and one MWCNT liquid treated with both surfactant and ultrasonication treatments. Each category consisted of six identical samples. It should be pointed out that the trial tests of NC liquid have not considered here due to the similar dispersed mechanism to NS [35]. The cement to sand ratio and water to cement ratio of the cement mortars were 1:2.5 and 1:2 respectively. The weight ratios of NS and MWCNT were $1 \mathrm{wt} . \%$ and $0.1 \mathrm{wt} . \%$ of cement weight respectively. The defoamer of polyether mixture was used to suppress the bubbles in cement mortar and construct dense cement samples. The cement mortar specimens were demolded after $24 \mathrm{~h}$ and placed in the $(23 \pm 2)^{\circ} \mathrm{C}$ water for 6 days, then cured in the concrete standard curing room.

The compressive strength and flexural tensile strength of various cement mortar specimens tested at $3 \mathrm{~d}, 7 \mathrm{~d}$ and $28 \mathrm{~d}$ are displayed in Fig. 7 and 8 , where $\mathrm{C}$ indicates the cement. The processing methods are denoted with "+", the "SFC" means the operation of surfactant, the "UV" means the operation of ultrasonication. For examples, sample C+NS+UV denotes a cement mortar specimen incorporating NS with ultrasonication process, $\mathrm{C}+\mathrm{MWCNT}+\mathrm{SFC}+\mathrm{UV}$ denotes a cement mortar specimen incorporating MWCNT with both surfactant and ultrasonication process.

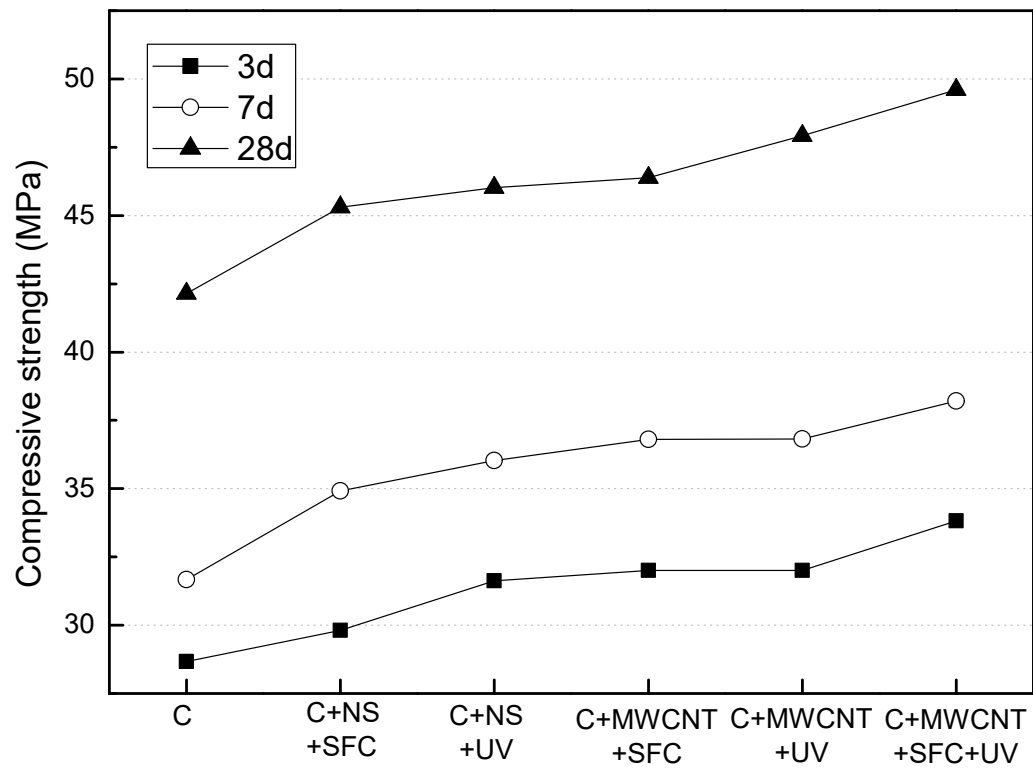

Fig.7 Compressive strength of cement mortar 


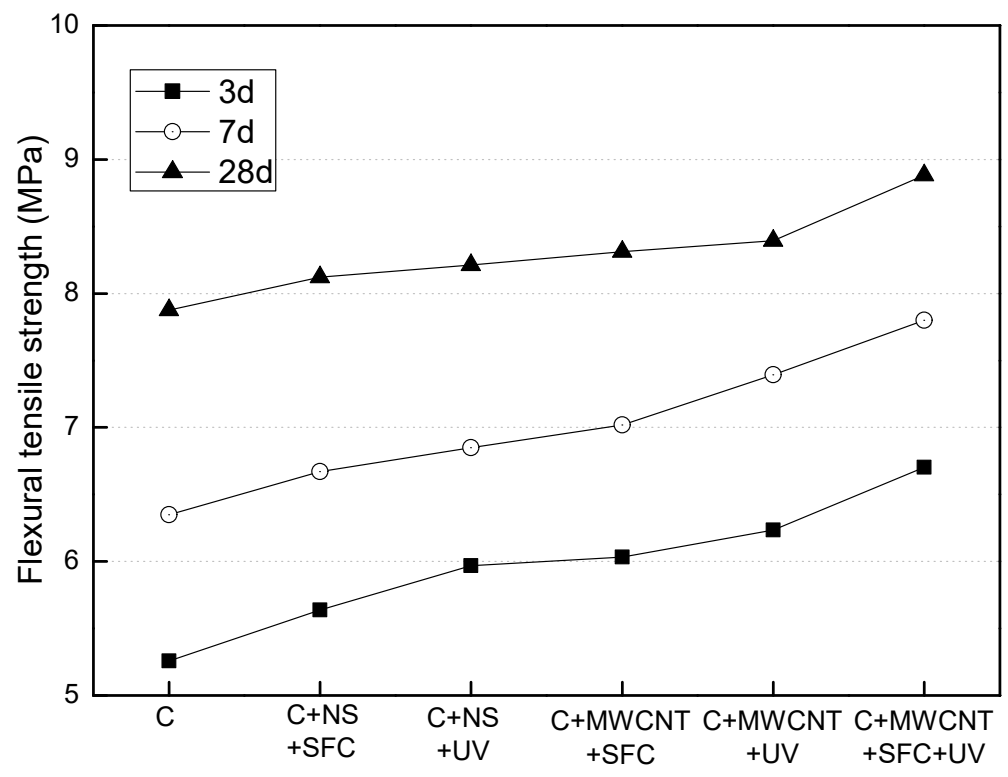

Fig.8 Flexural tensile strength of cement mortar

Based on Fig. 7 and 8, both the compressive strength and flexural tensile strength of cement mortar increased with the age reasonably. The NS or MWCNT treatment improved the both the compressive strength and flexural tensile strength of cement mortar slightly, with surfactant and ultrasonication processes, the improvement tended to be more obvious, especially for the combined treatment of both surfactant and ultrasonication. Hence, all the nano-particles liquids used in the RAC-RCBA specimens of the following 3d-, 7d- and 28d-compressive and $28 \mathrm{~d}$-split tensile tests were duilted with surfactant, and the additional ultrasonication combined with surfactant were performed in two categories of NS modified and MWCNT modified RAC-RCBA specimens.

\section{Results and Discussion}

\subsection{Slump of fresh concrete}

The slump tests were performed to investigate the workability of fresh untreated RAC and the nano-particle modified RAC according to the standard GB/T 50080-2002 [60]. The average tested slump values and the coefficients of variation (COV) are shown in Fig. 9. The slump of untreated RAC without nano-particles decreased with an increase of the replacement ratio of the RAs. The slump of RAC decreased compared to that of NAC (i.e., specimens RAC-0\%). The reasons might be attributed to the large porosity and the high water absorption ratio of the recycled clay brick aggregates which led to a reduction of mixing free water and an increase of the viscosity of the mix. As seen in Fig. 9(b), the slump of NS-modified RAC also decreased with an increase of the replacement ratio of RAs, and the slump decreased significantly with the increase of the NS dosage from $1 \%$ to $2 \%$. This might be interpreted by the large surface area and more free water absorption of the NS particles [27]. The first TSMA method (i.e., MI) adopting UV approach also decreased the slump of the RAC, which could be explained by the higher water absorption with better dispersion of NS admixture. For NC-modified RAC, the similar effect of ultrasonication and MI on the slump was also found as shown in Fig. 9(c). The slumps of NC-modified RAC were larger than those of the corresponding NS-modified RAC. The MWCNT-modified RAC exhibited the lowest slump 
considering the positive effect of MWCNT on the early hydration process of the cementitious matrix [56]. Overall, both the existing RAs and the addition of nano-materials could weaken the workability of RAC due to the high water absorptions of the RAs and the three types of nano-particles used in this study. The processes of promoting the dispersion using the surfactant and ultrasonication approaches resulted in the reduction in the slump values of RAC due to the enlarged surface area and increased water absorption of the nano-particles.

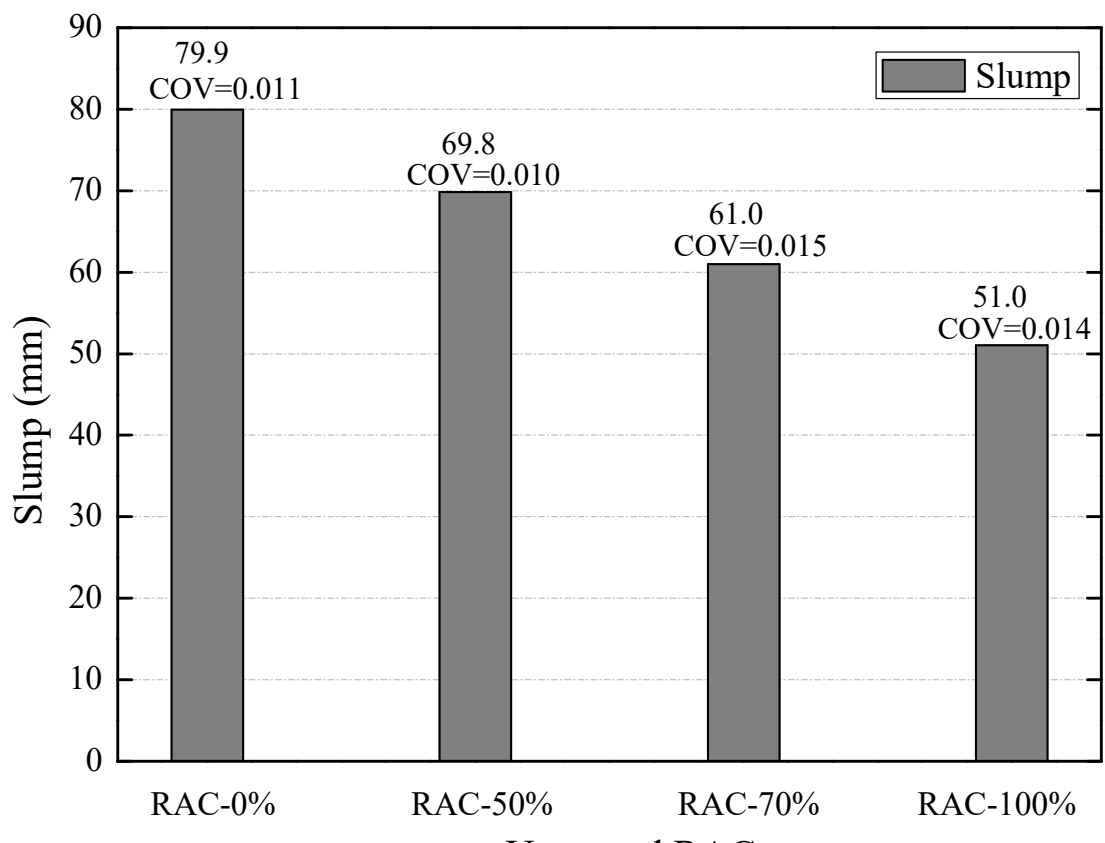

Untreated RAC

(a)

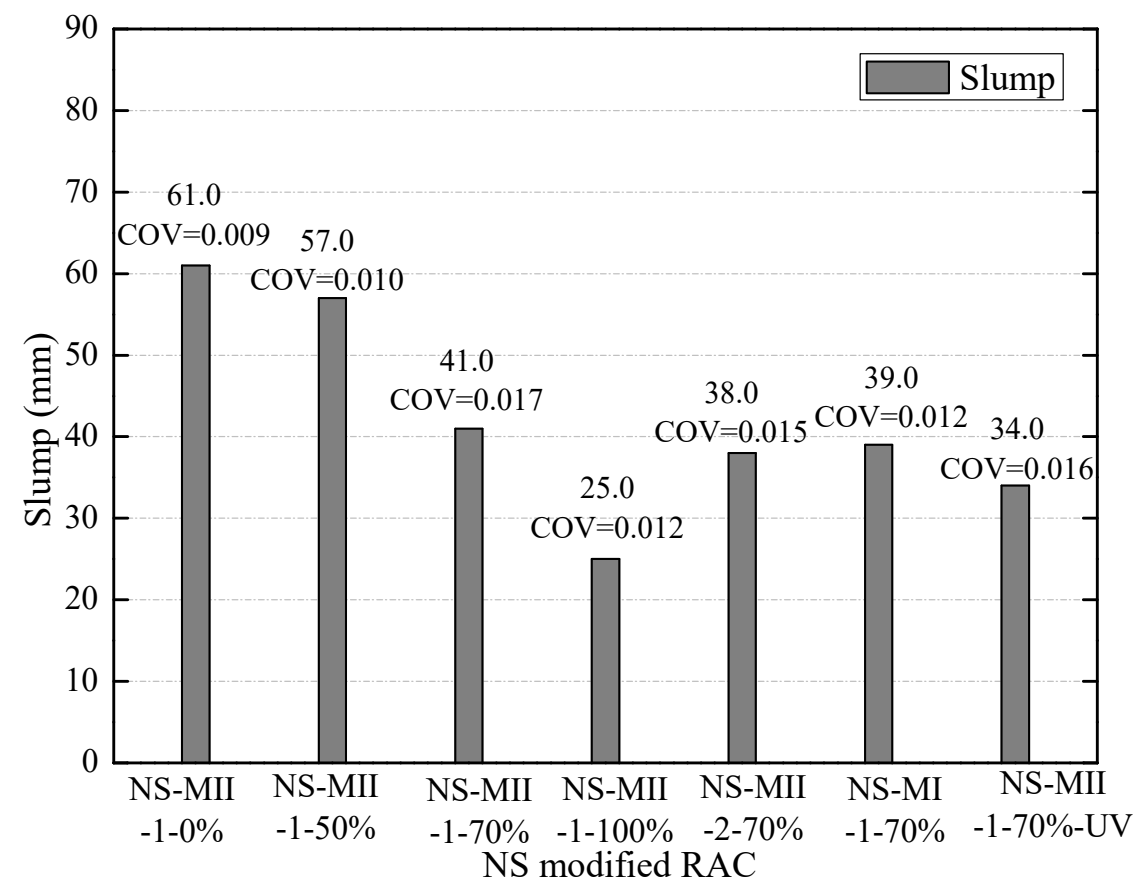

(b) 


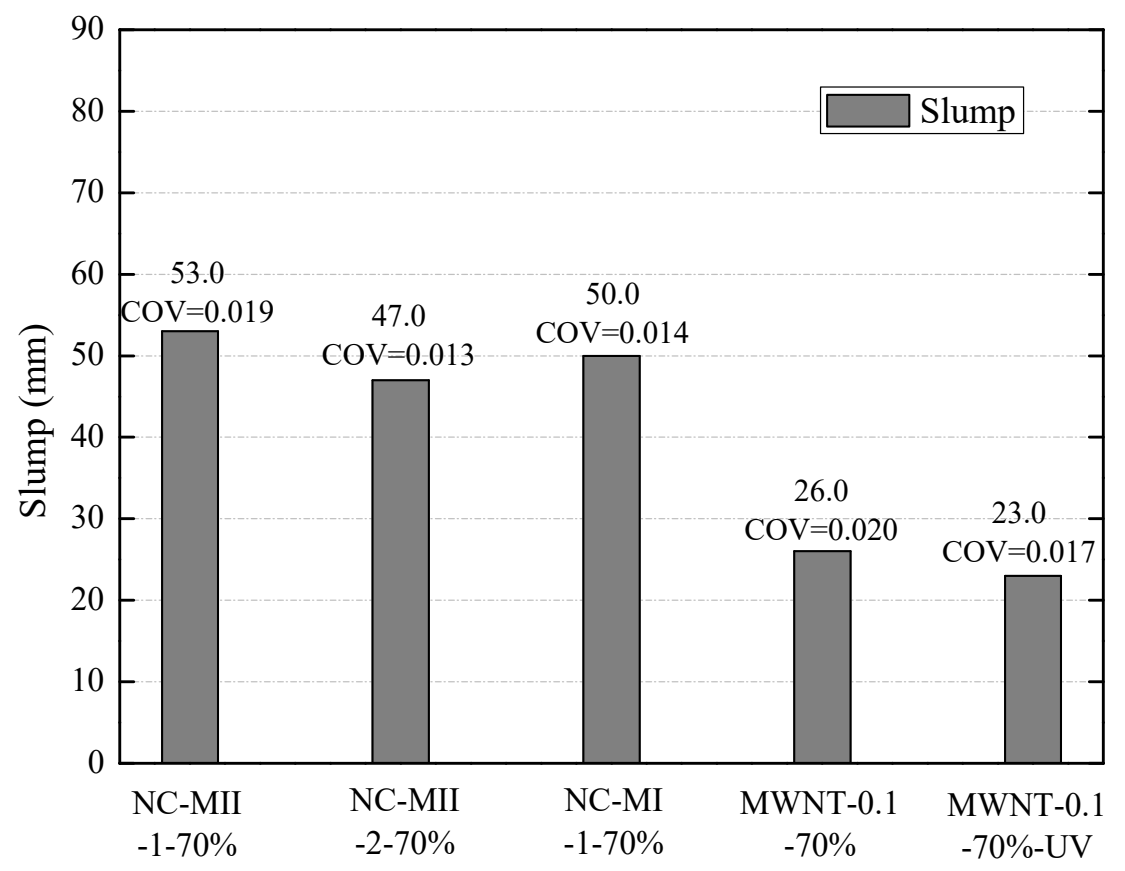

NC modified RAC and MWNT modified RAC

(c)

Fig.9 Slump values of RAC and RAC modified with nanoparticles: a) untreated RAC b) NS modified RAC and c) NC modified RAC and MWCNT modified RAC

\subsection{Failure modes and crack propagation}

The failure modes of nano-particle modified RAC under compressive load were observed at different stages of the loading. It was found that the crack propagating process was similar for all the RAC specimens. There were small cracks developed in the concrete when the compressive loading was within $30 \%$ of the peak load and these micro cracks concentrated around the ITZ according to the previous studies $[18,23]$. During the second stage when the compressive loading was more than $30 \%$ but lower than $80 \%$ of the peak load, more longitudinal cracks occurred than the transvers cracks. When the compressive load was beyond $80 \%$ but less than $100 \%$ of peak load, the cracks developed dramatically with tearing sounds. After reaching the peak load, the external mortar of RAC cubic specimens fell off and the specimen was crushed.

The final crack patterns of untreated NAC and RAC, NS modified RAC cubic specimens are shown in Fig. 10. In general, the failure patterns of different nano-particle modified RAC were the same as that of NAC or that of RAC with a diagonal pyramid rupture. Compared with the NAC, most RAs in the RAC were crushed under the compressive load, while most coarse NAs maintained unbroken. This phenomenon could be interpreted by the lower crushing index of NAs (i.e., 10.7\%) compared to that of the RAs (i.e., 17.3\%). 


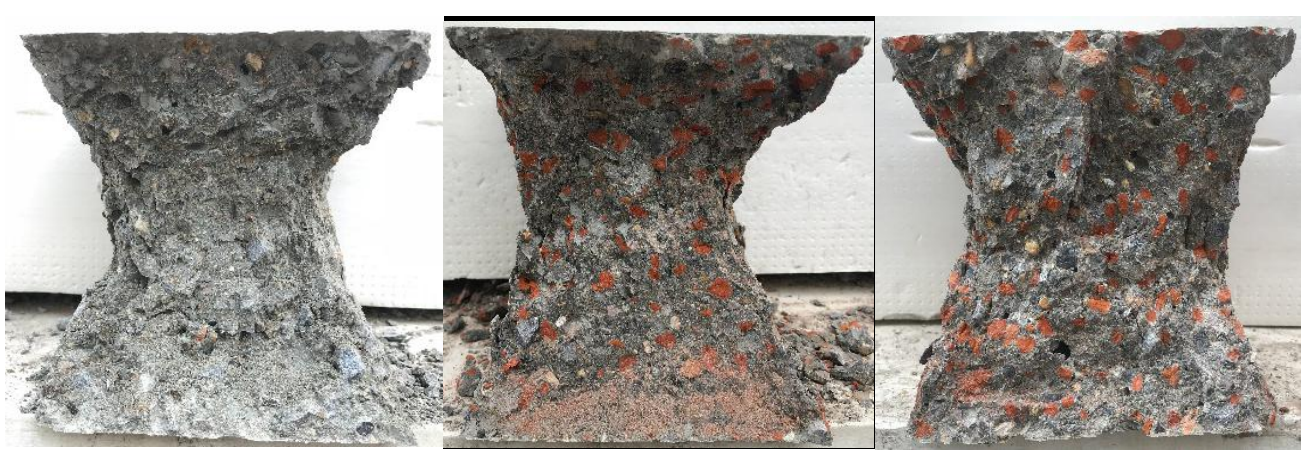

(a)

(c)

Fig.10 Failure modes under compression load: a) untreated NAC, b) untreated RAC and c) 1wt.\% NS modified RAC

Fig11 shows the failure modes of untreated NAC and RAC, NS modified RAC cubes under split tensile load. The ruptured patterns of NS modified RAC were also similar to that of untreated NAC or the untreated RAC with one single longitudinal crack. Overall, the addition of nano-materials did not change the failure mode of the RAC under either the compressive or split tensile load.

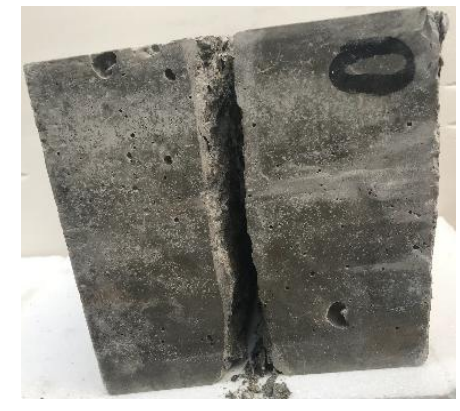

(a)

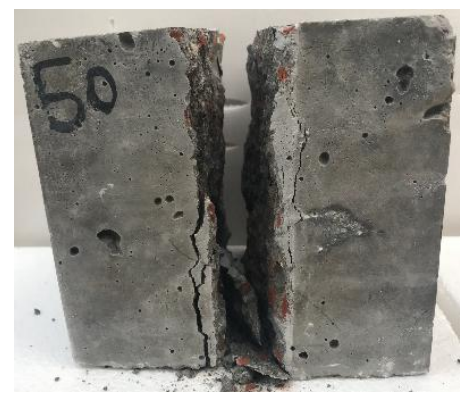

(b)

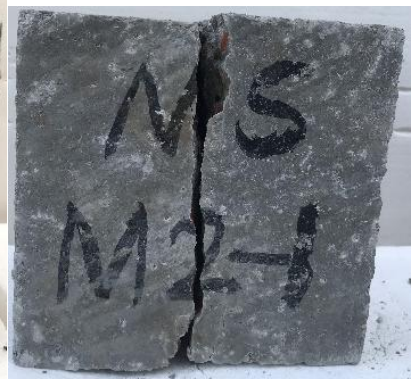

(c)

Fig.11 Failure modes under split tensile load: a) untreated NAC, b) untreated RAC and c) NS modified RAC

\subsection{Compressive strength}

The results of compressive strength for the different RAC specimens tested at 3-day, 7-day and 28-day are listed in Figs. 12-15. For untreated RAC cubic specimens with different replacement ratios of RAs, an increase in replacement ratio of the RAs led to a reduction in the 3d-and 7d-compressive strength due to the higher crushing index of RAs compared with that of NAs. The reduction in the compressive strength of RAC became insignificant with an increase in the replacement ratio of RAs. Specifically, the difference in the compressive strength was marginal when the replacement ratios increased from $70 \%$ to $100 \%$. For instance, when the replacement ratio of RAs increased from $0 \%$ to $50 \%$, the reduction ratios in the compressive strength for RAC at $3 \mathrm{~d}, 7 \mathrm{~d}$ and $28 \mathrm{~d}$ were $10.6 \%, 10.6 \%$ and $10.6 \%$, respectively. While increasing the replacement ratios from $70 \%$ to $100 \%$, the reduction ratios in the compressive strength of RAC tested at $3 \mathrm{~d}, 7 \mathrm{~d}$, and $28 \mathrm{~d}$ were $5.9 \%, 5.8 \%$ and $4.6 \%$, respectively as Fig. 12. 


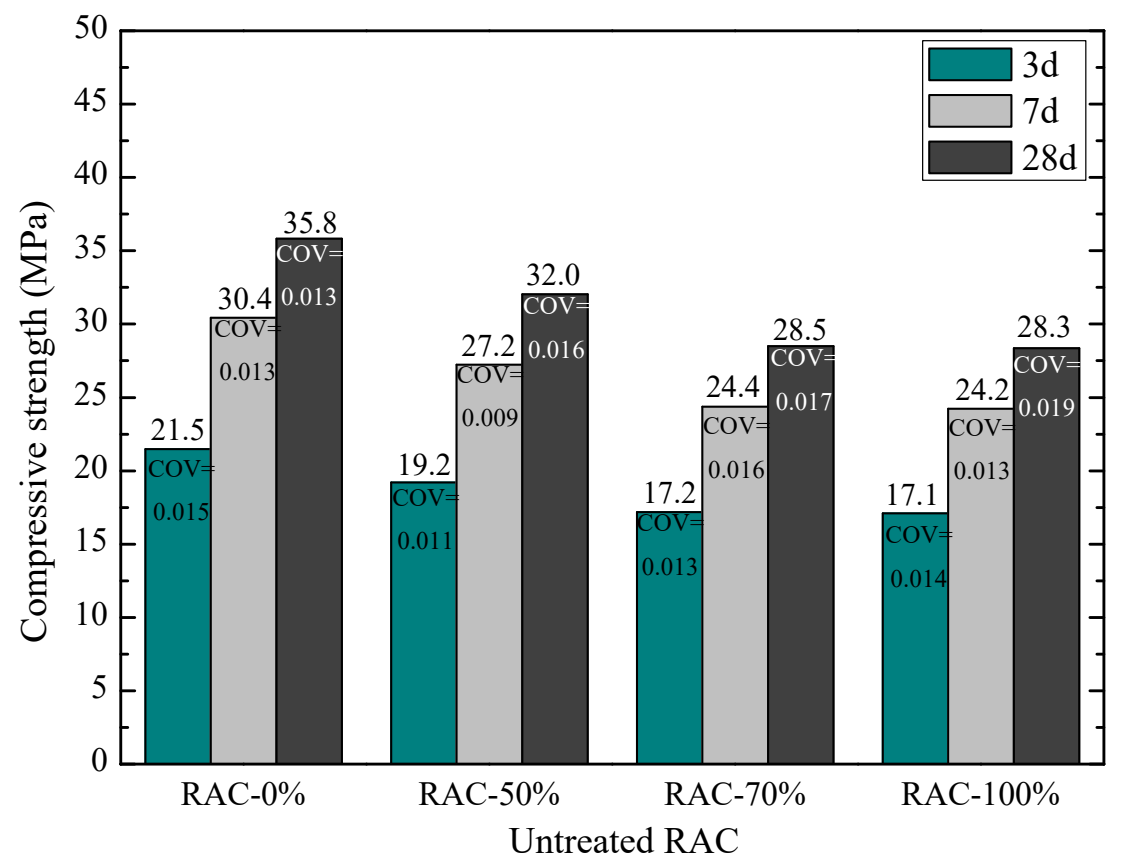

Fig. 12 Compressive strength of untreated RAC

Fig 13 shows the compressive strength of NS modified RAC specimens with different replacement ratios of RAs tested at $3 \mathrm{~d}, 7 \mathrm{~d}$ and $28 \mathrm{~d}$. Generally, the compressive strength of the specimens increased with the extension of the curing duration. The $7 \mathrm{~d}-$ and $28 \mathrm{~d}$-compressive strength of RAC specimens with NS incorporation increased compared to those of untreated RAC corresponding to the same replacement ratios of the RAs, as shown in Figs. 10 and 11. For 7d-compressive strength of RAC incorporating NS specimens, the increments compared to those of untreated RAC counterparts at $7 \mathrm{~d}$ were around $4.0 \% \sim 12.3 \%$. For $28 \mathrm{~d}$-compressive strength of RAC incorporating NS specimens, the increments compared to those of untreated RAC counterparts at $28 \mathrm{~d}$ were around $4.1 \%-16.8 \%$. It could be indirectly found from the improvement on the compressive strength that the NS plays one crucial role in filling the micro voids of both coarse and fine aggregates and promoting the mix of concrete mixture. The 3d-compressive strength of NS-modified RAC specimens showed an insignificant trend that the 3d-compressive strength of NS-modified RAC with $0 \%$ and $100 \%$ specimens were slightly lower than those of corresponding untreated RAC with $0 \%$ and $100 \%$ specimens. The possible reasons for the opposite variation trends of the early-age compressive strength of NS modified RAC could be the reaction duration of the NS with the cement mortar and mixing water, and that postponed the development of early-age compressive strength. 


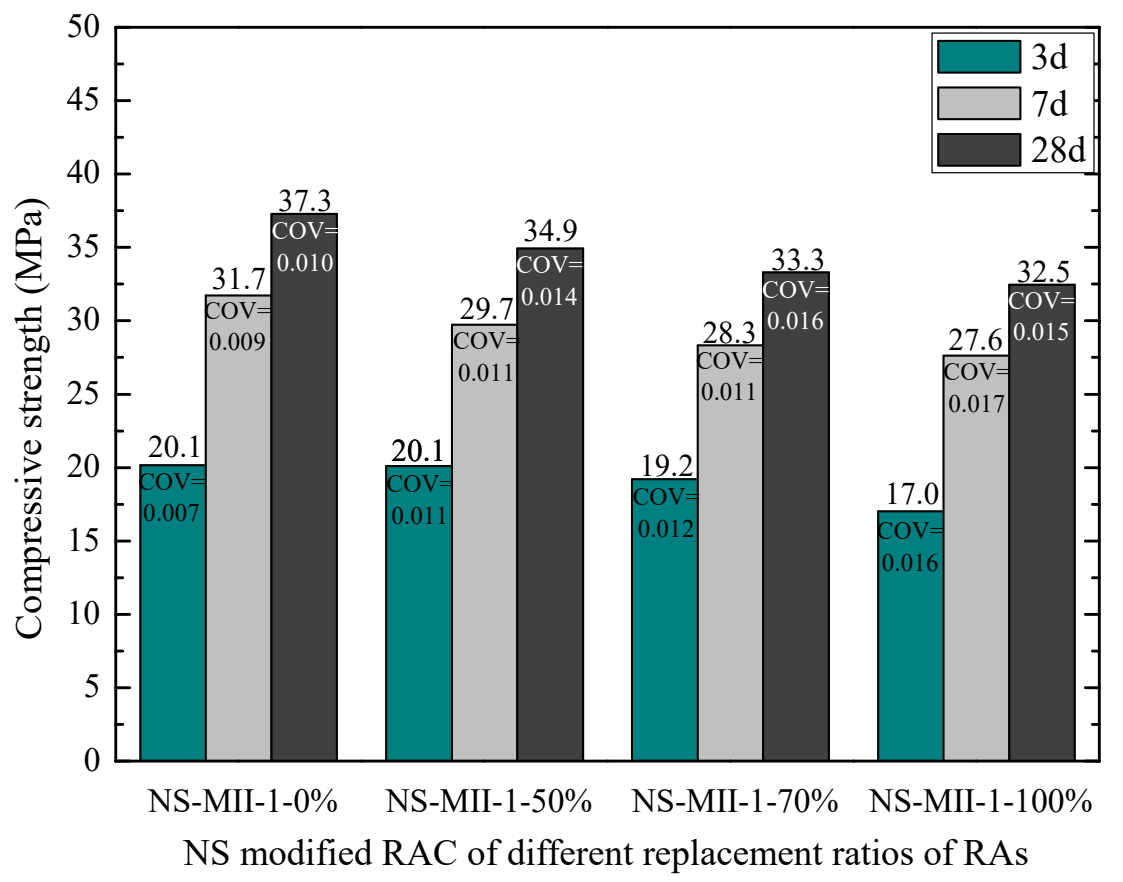

Fig. 13 Compressive strength of NS-modified RAC with different replacement ratios of RAs

Fig.14 showed the 3d-, 7d- and 28d-compressive strength of the NS-modified RAC with different TSMAs (i.e., MI and MII), dosages of NS (i.e., 1 wt.\% and 2 wt.\%) and the participation of ultrasonication. Generally, the specimens with an increase of NS dosage or ultrasonication process showed a higher $3 \mathrm{~d}-, 7 \mathrm{~d}-$ and $28 \mathrm{~d}$-compressive strength, e.g., the NS-MII-2-70\% specimens with $2 \%$ dosage of NS and NS-MII-1-70\%-UV specimens with ultrasonication process presented $15.8 \%$ and $20.3 \%$ higher $28 \mathrm{~d}$-compressive strength than that of the NS-MII-1-70\% specimen, respectively. The increased strength could be interpreted by more NS used and better dispersion with extra ultrasonication that led to a better filling effect of the internal voids, which accelerating the motion of nano-particles, and further promoting the nano-particle dispersion and mixing with the concrete. For specimens NS-MI-1-70\% and NS-MII-1-70\%, it could be found that the concrete mixture by the first TSMA could promote the $3 \mathrm{~d}$ - and $7 \mathrm{~d}$-compressive strength of RAC better than the specimens treated by the second TSMA, but the first TSMA resulted in less increments of 28d-compressive strength than the specimens with the second TSMA. This might be because the NS admixture were initially mixed with dry RAs and the NS preferentially densified the microstructures of RAs. While the initial improvement of NS was concentrated the promoting function on the ITZ-1 regardless of another two ITZs in Fig. 1(b). For the second TSMA, the NS admixture was mixed with the mixture of all concrete raw materials so that the NS could benefit for all ITZs and promote the final compressive strength of RAC more apparently. 


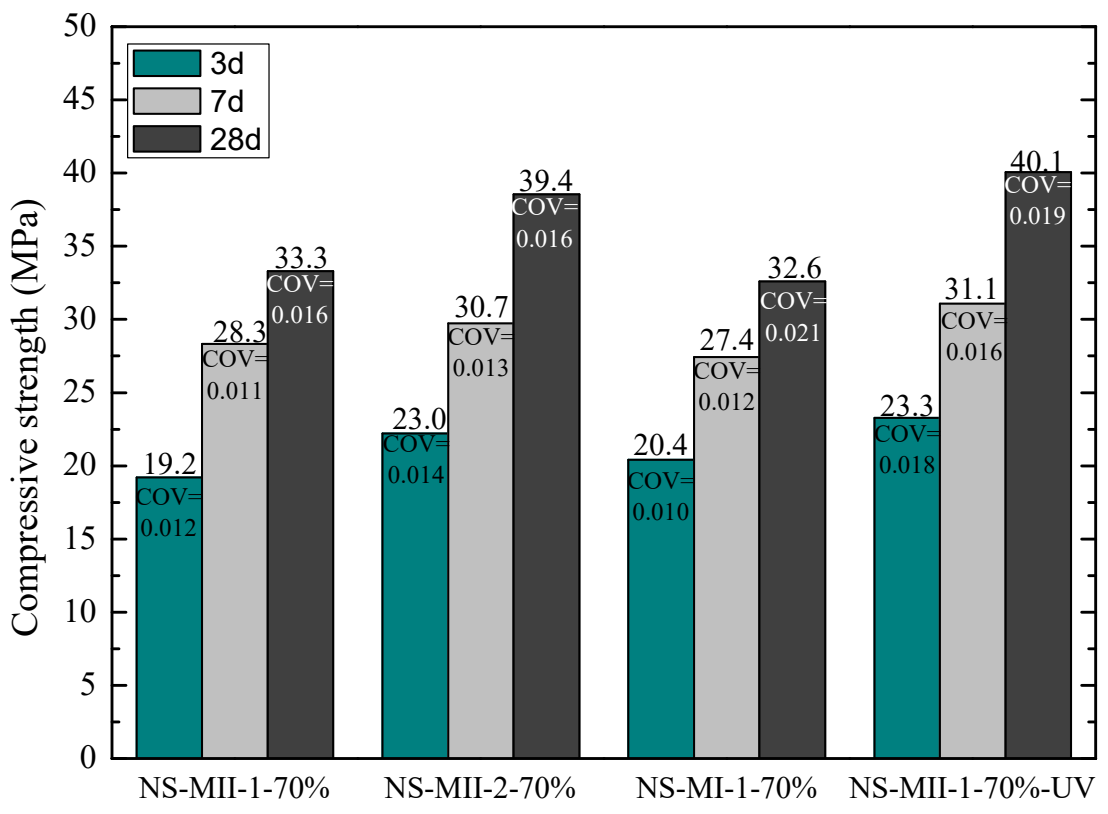

NS modified RAC of different mixing methods and dosage of NS

Fig. 14 Compressive strength of NS-modified RAC with different mixing methods and dosages of NS

The Fig. 15 showed the $3 \mathrm{~d}-, 7 \mathrm{~d}-$ and $28 \mathrm{~d}$-compressive strength of respective NC modified RAC specimens and MWCNT modified RAC specimens. The addition of NC improved the $28 \mathrm{~d}$-compressive strength of RAC and 3d-, 7d- and $28 \mathrm{~d}$-compressive strength increased more with an increase of $\mathrm{NC}$ dosages, while for $\mathrm{NC}$ modified RAC specimens with $1 \mathrm{wt} . \% \mathrm{NC}$ admixture, the 3d- and 7d-compressive strength were lower than those of the untreated RAC specimens, indicating the postpone of the early-age strength development when applying NC in RAC. The NC modified RAC specimens with MII mixing method exhibited higher 3d-, 7dand 28d-compressive strength than NC modified RAC specimens with MI. The MWCNT modification resulted in the highest growth of 28d-compressive strength of RAC with the least dosage compared to NS modified RAC and NC modified RAC. The ultrasonication process also increased the compressive strength of the MWCNT-modified RAC. The compressive strength increments of MWCNT-modified RAC with and without ultrasonication compared to that of the untreated RAC were $38.7 \%$ and $42.2 \%$, respectively. 


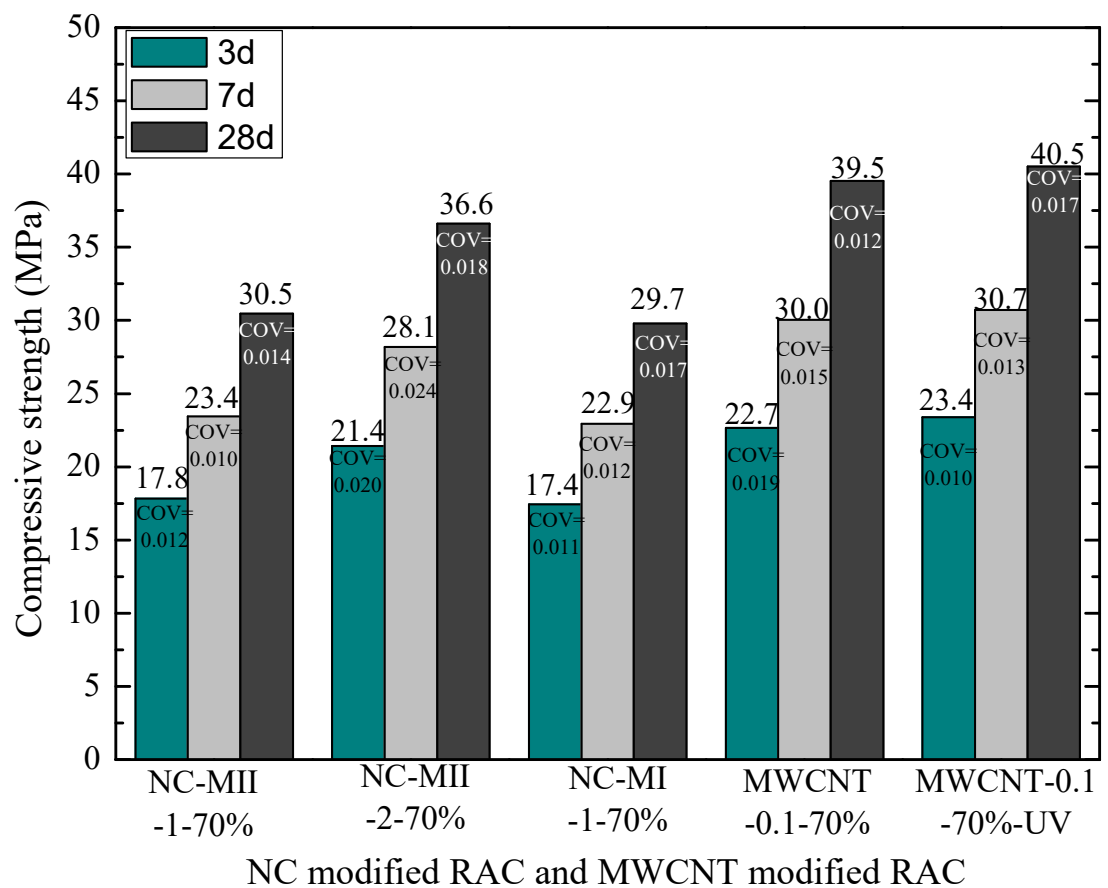

494

Fig. 15 Compressive strength NC modified RAC and MWCNT modified RAC

Therefore, an increase of the dosage of both NS and NC incorporation for RAC (up to $2 \mathrm{wt} . \%$ of cement) increased the 3d-, 7d- and 28d-compressive strength of RAC. Among these three kinds of nano-materials, the MWCNT modification exhibited the largest improvement on the compressive strength of the RAC, followed by the 2 wt.\% NS modification, the 2 wt. $\%$ NC modification, the $1 \mathrm{wt} . \% \mathrm{NS}$ modification and the $1 \mathrm{wt} . \% \mathrm{NC}$ modification successively. The second TSMA resulted in superior compressive strength of the RAC compared with the first TSMA, and the treated specimens with ultrasonication combined with SFC treatment process also exhibited higher compressive strength than those with SFC treatment alone. The improvement on the compressive strength of nanoparticles modified RAC could be predicted from the former compression tests on cement mortar. The compressive strength of concrete could be generally determined by the cement strength and water-cement ratio, since the nanoparticle admixtures have optimistic influence on the compressive strength of cement mortar, the resulting promotion on the compressive strength of concrete was foresaw available.

Table 7 Comparison of compressive strength with available test results in literature [27, 54-55]

\begin{tabular}{cccccccccccc}
\hline & \multicolumn{8}{c}{ Increments of compressive strength (MPa) } \\
\cline { 2 - 10 } Data source & $0.75 \%$ NS & $1.5 \%$ NS & \multicolumn{1}{c}{$1 \%$ NS } & \multicolumn{2}{c}{$2 \%$ NS } & \multicolumn{2}{c}{$3 \%$ NS } \\
& $7 \mathrm{~d}$ & $28 \mathrm{~d}$ & $7 \mathrm{~d}$ & $28 \mathrm{~d}$ & $7 \mathrm{~d}$ & $28 \mathrm{~d}$ & $7 \mathrm{~d}$ & $28 \mathrm{~d}$ & $7 \mathrm{~d}$ & $28 \mathrm{~d}$ \\
\hline Li et al. [54, 55] & - & - & - & - & 6.0 & 6.1 & 7.0 & 8.5 & - & - \\
Bibhuti et al. [27] & 1.1 & 2.8 & 1.7 & 4.3 & - & - & - & - & 3.8 & 6.2 \\
Present study & - & - & - & - & 3.9 & 4.8 & 6.3 & 10.9 & - & - \\
Relative error & \multicolumn{1}{c}{ $\pm 0.94 \mathrm{MPa}$ for 7d, \pm 1.66 MPa for 28d-compressive strength } \\
\hline
\end{tabular}


It should be noted here that the test compressive strength was also compared with experimental results obtained in the existing literatures, as listed in Table 7 [27, 54-55]. The $7 \mathrm{~d}$ and $28 \mathrm{~d}$ compressive strength of similar specimens were provided. For Li's studies [54-55], the $7 \mathrm{~d}$ and $28 \mathrm{~d}$ compressive strength of NS modified recycled concrete specimens with $1 \%$ and $2 \%$ dosages of NS were offered, the increment of compressive strength varied from $20.7 \%$ to $24.9 \%$. In study of Bibhuti [27], the dosages of NS were $0.75 \%, 1.5 \%$ and $3 \%$, respectively, and the $7 \mathrm{~d}$ and $28 \mathrm{~d}$ compressive strength of NS modified recycled concrete specimens were also given. Considering the differences of test set in above studies, the relative errors of $7 \mathrm{~d}$ and $28 \mathrm{~d}$ compressive strength were the mean deviation based on the classification as low NS dosage category $(0.75 \%, 1 \%$ and $1.5 \%)$ and high NS dosage category ( $2 \%$ and $3 \%$ ), respectively. The relative errors were $\pm 0.94 \mathrm{MPa}$ for $7 \mathrm{~d}$ and $\pm 1.66 \mathrm{MPa}$ for $28 \mathrm{~d}$-compressive strength, respectively, indicating the reasonability and accuracy of the data in present study.

\subsection{Split tensile strength}

4.4.1 Tested results and discussion

Fig. 16 shows the variation of split tensile strength of nano-particle modified RAC. As shown in Fig. 16(a), the split tensile strength of both untreated RAC and RAC incorporating nano- $\mathrm{SiO}_{2}$ decreased with an increase of the replacement ratios of the RAs. All the three types of nanoparticles used in the RAC improved the split tensile strength, the MWCNT modification with the least dosages exhibited the most remarkable enhancement in the split tensile strength of the RAC, i.e., $16.9 \% \sim 20.4 \%$ increment compared to corresponding plain RAC-RCBA specimens with the same 70\% replacement ratios of RAs, while those increments of NS modification were around $6.0 \% \sim 20.8 \%$ and $4.9 \% \sim 11.4 \%$ for $\mathrm{NC}$ modification. An increase in dosage of both $\mathrm{NS}$ and $\mathrm{NC}$ also caused an increase in split tensile strength of the RAC, i.e., $7.3 \%$ increment rate of $2 \%$ dosage of NS modified RAC than $1 \%$

The MII mixing method used in modified RAC exhibited slightly higher split tensile strength than the specimen treated by MI, e.g., the split tensile strength of NS modified RAC using MII was 2.4\% larger than that of using MI, and the split tensile strength of NC modified RAC using MII was $0.4 \%$ larger than that of using MI. Better effects of MII over MI could be due to the same reasons as that in the scenario of compression tests in Section 4.2: MII resulted in a comprehensive enhancement in the all the three ITZs in Fig 1(b), while the first TSMA only acted on the ITZ-1 of the RAs. Nevertheless, the ultrasonication process presented a slight improvement on the split tensile resistance on the RAC when incorporating NS or MWCNT, and that was different from the scenario of compression test. The cause for this difference could be that the split tensile strength is primarily dependent on the split tensile strength of mixture materials themselves, e.g., the split tensile strength of concrete itself or the effect of nano-materials, and the ultrasonication process could not change the split tensile strength of concrete itself.

The increased split tensile strength of nanoparticles modified RAC could also be expected from the increased flexural tensile strength of cement mortar. As explained, the strength of natural aggregates and sand were generally much higher than the strength of set cement, the 
rupture plane of concrete generally occurred on the interface between cement and aggregates or on the cement. The strength of concrete mainly depends on the strength of the set cement and the interface with aggregates, which directly determine the cement strength and water-cement ratio. Therefore, the promotion of split tensile strength of RAC would consequently occur.

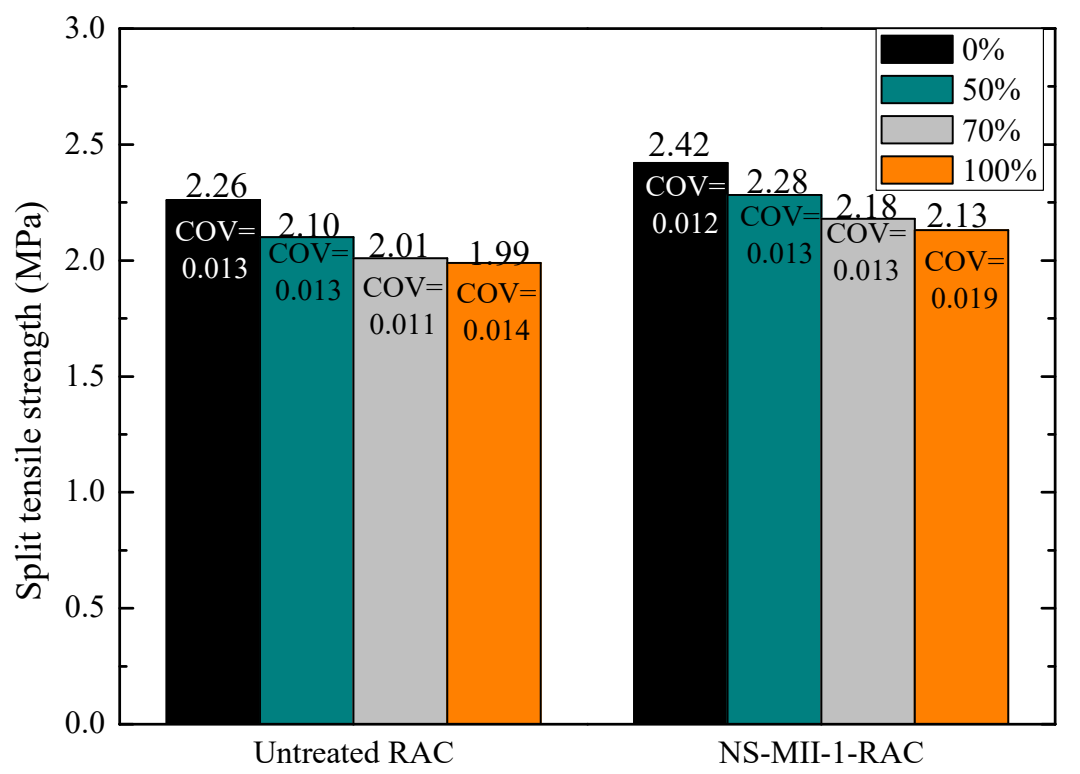

Untreated RAC and NS modified RAC with different replacement ratios of RAs

(a)

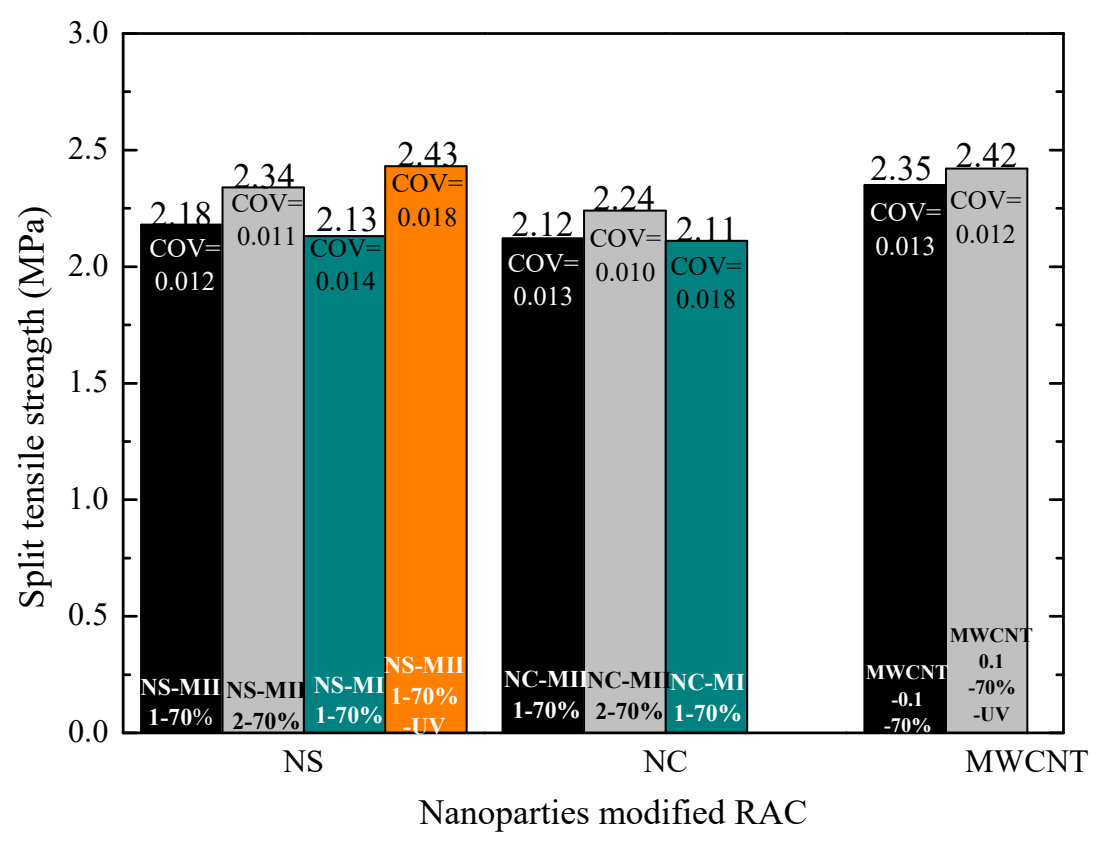

(b)

Fig. 16 Variation of split tensile strength: a) untreated RAC and NS-modified RAC with different replacement ratios of RAs, b) NS-modified RAC, NC-modified RAC and MWCNT-modified RAC with different mixing methods and dosages of NS or NC

Besides, the test split tensile strength in this present study was also compared with the 
experimental results provided by Bibhuti [27], as listed in Table 8. The average difference was barely $\pm 0.017 \mathrm{MPa}$ for $28 \mathrm{~d}$-split tensile strength, indicating the reliability of the tests in present study.

Table 8 Comparison of split tensile strength with available test results in literature [27]

\begin{tabular}{cccccc}
\hline \multirow{2}{*}{ Data source } & \multicolumn{5}{c}{ Increments of 28d-split tensile strength (MPa) } \\
\cline { 2 - 6 } & $0.75 \%$ NS & $1.5 \%$ NS & $1 \%$ NS & $2 \%$ NS & $3 \%$ NS \\
\hline Bibhuti et al. [27] & 0.14 & 0.24 & - & - & 0.34 \\
Present study & - & - & 0.17 & 0.33 & - \\
Relative error & & \pm 0.017 MPa for 28d-split tensile strength \\
\hline
\end{tabular}

\subsubsection{Evaluation by design standards}

A comparative study between the test results and the split tensile strength values calculated by formulations presented in different concrete design codes (Table 9 [56-60]) was conducted and shown in Fig.17, where $f_{\text {st }}$ is the predicted split tensile strength, $f_{\mathrm{c}}$ is the corresponding compressive strength of specimens. The compressive strength $\left(f_{c}\right)$ for all the formulas listed in Table 9 referred to $28 \mathrm{~d}$-compressive strength based on tests on cubic specimens. The cubic specimens with size of $150 \times 150 \times 150 \mathrm{~mm}^{3}$ or cylindrical specimens with size of diameter $\times$ height $=150 \times 300 \mathrm{~mm}^{2}$ are generally used as the standard specimens in the split tensile strength test of concrete. It should be noticed that the split tensile strength in all the standard relations referred to the split tensile strength of cylindrical specimens. Therefore, a correction factor of 0.8 is adopted for converting the tested 28-day compressive strength $\left(f_{\mathrm{c}}\right)$ of cubic specimens to cylindrical strength [63]. Since the cubic specimens were selected to test the split tensile strength in this research, the size effect was considered in the code calculated values as Eq. (1) [64], where the $f_{s t, 150}$ is the 28-day split tensile strength of cubic specimens with size of $150 \times 150 \times 150 \mathrm{~mm}^{3}, A$ is the area of split surface. Therefore, the relationship between the calculated split tensile strength values $f_{s t, c o d e}$ of cylindrical specimens based on the codes and the tested cubic specimens $f_{s t, 150}$ in this research was $f_{\text {st }, \text { code }} / f_{\text {st }, 150}=0.83$.

$$
f_{\text {st }} / f_{\text {st }, 150}=3.606 A^{-0.136}
$$

Based on Fig.17, the test data were coincided with the calculated values based on Spanish code formula [59], and other code formulas overestimated the split tensile strength values.

Table 9 Formulations of relationship between compressive strength and split tensile strength of concrete in different concrete design codes

\begin{tabular}{ll}
\hline & Split tensile strength \\
\hline ACI 318 [56] & $f_{s t}=0.56 \times \sqrt{ } f_{c}$ \\
GB 50010 [57] & $f_{s t}=0.19 \times f_{c}^{0.75}$ \\
CEB [58] & $f_{s t}=1.56 \times\left(\frac{f_{c}-8}{10}\right)^{2 / 3}$ \\
EHE [59] & $f_{s t}=0.21 \times f_{c}^{2 / 3}$ \\
NBR 6118 [60] & $f_{s t}=0.3 \times f_{c}^{2 / 3}$ \\
\hline
\end{tabular}


602

603

604

605

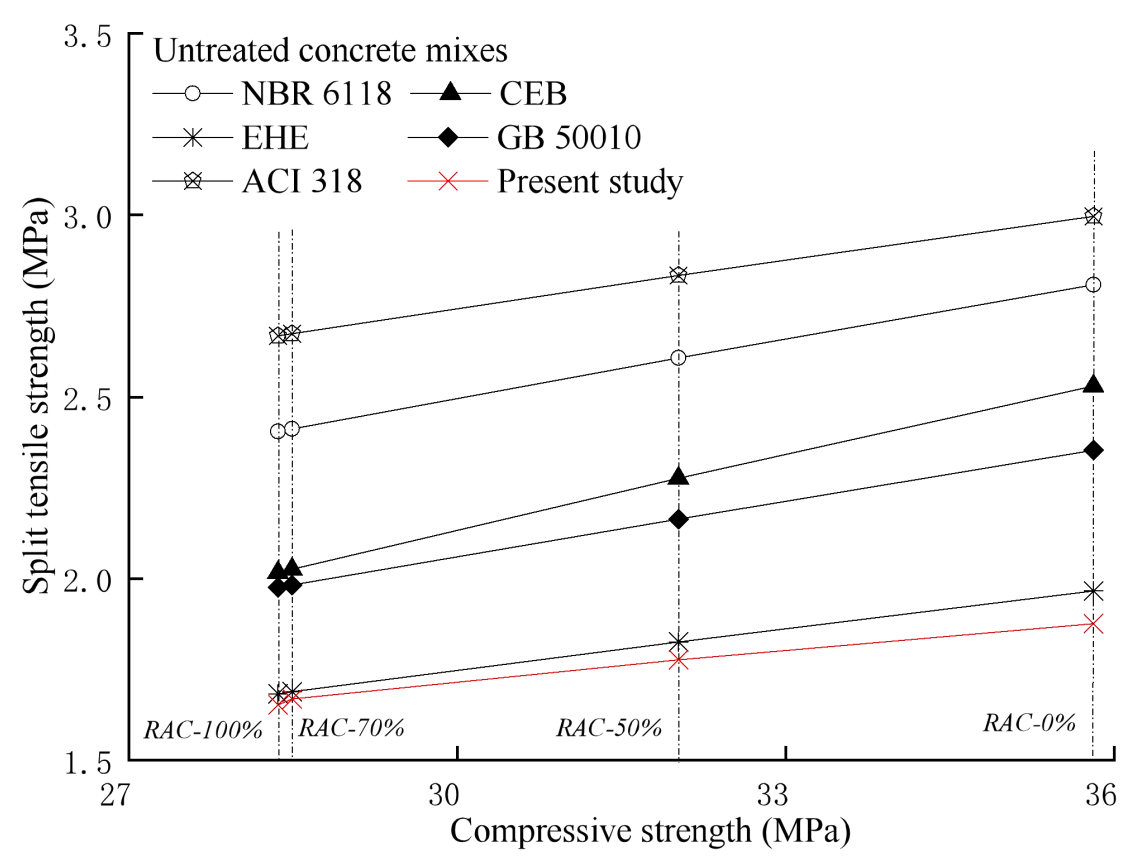

(a)

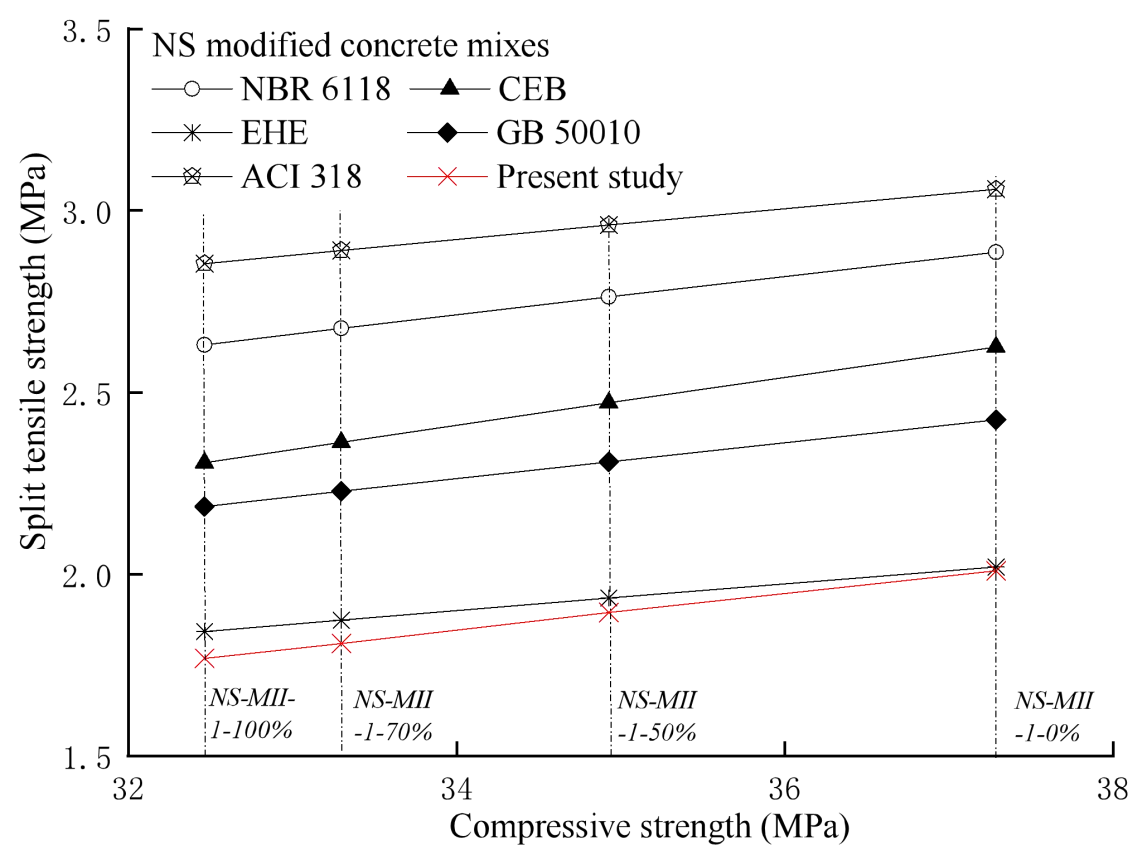

(b) 
606

607

608

609

610

611

612

613

614

615

616

617

618

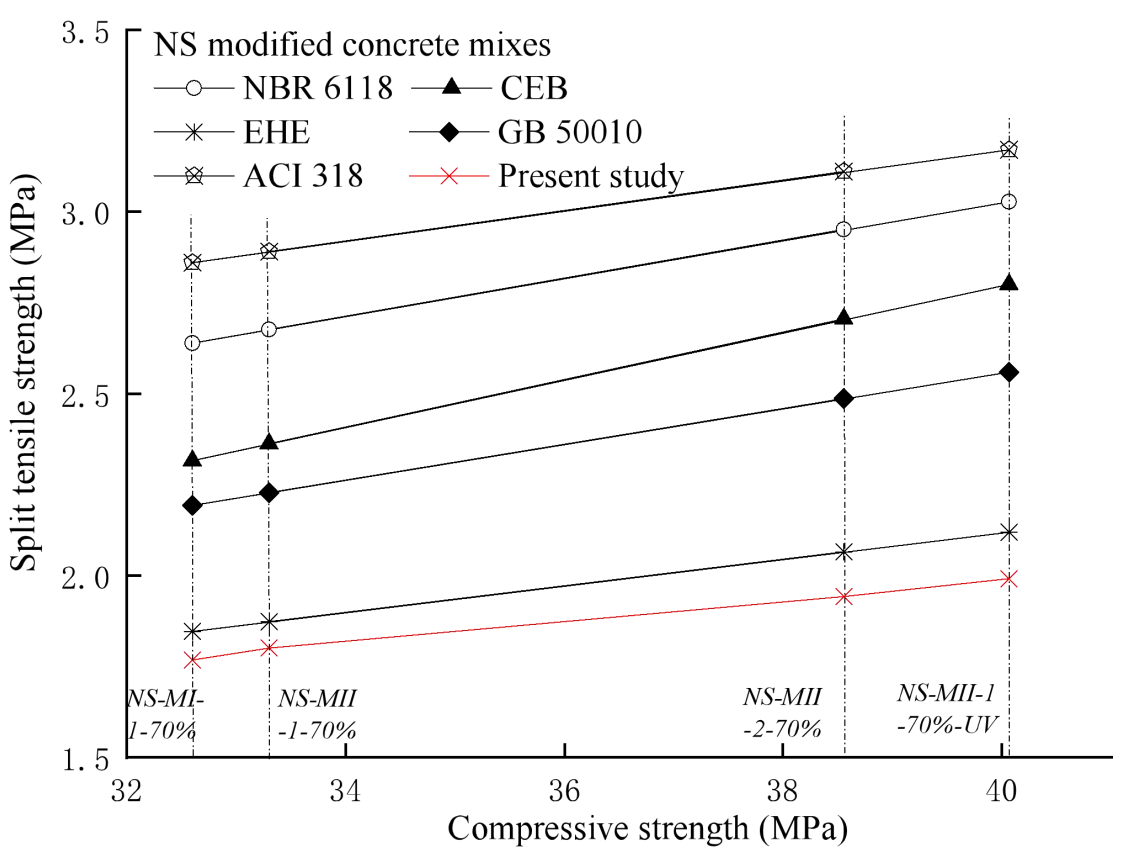

(c)

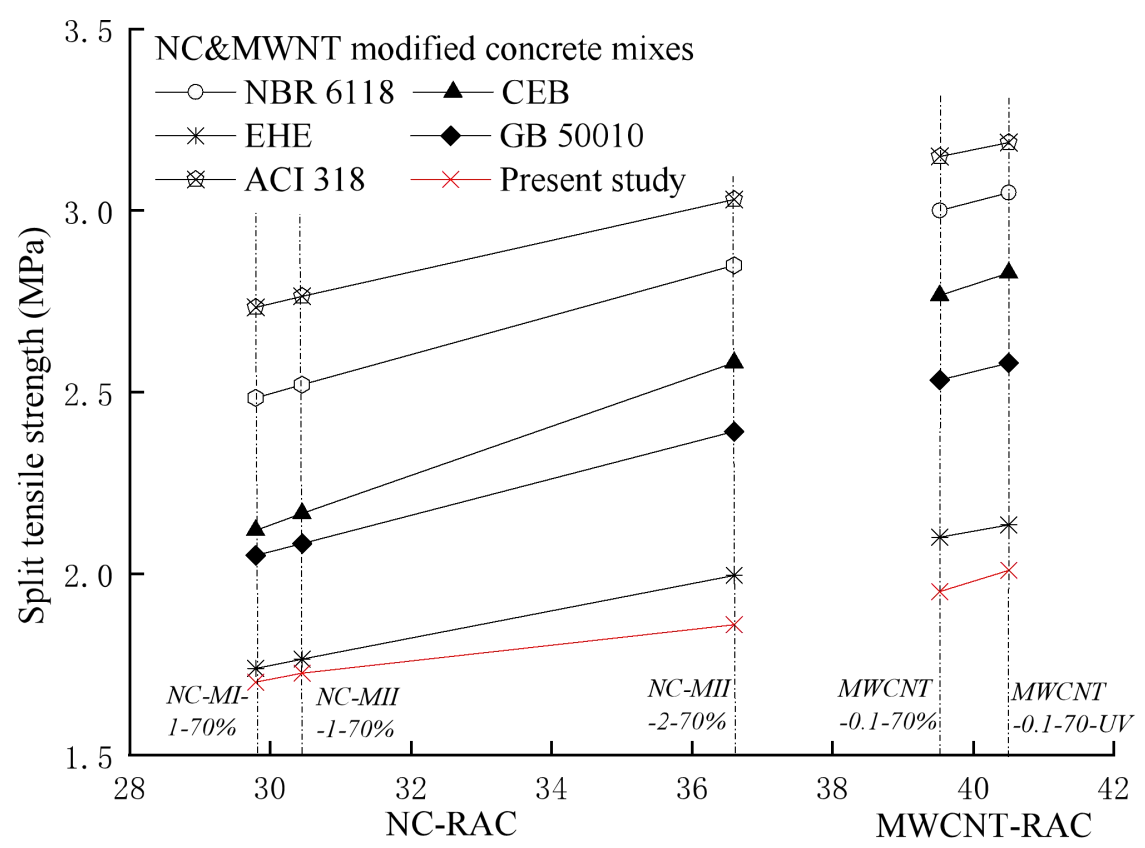

Compressive strength (MPa)

(d)

Fig. 17 Comparison of split tensile strength with Standard formulas: (a) untreated RAC, (b)

NS modified RAC with different replacement ratios of RAs, (c) NS-modified RAC with different mixing methods and dosages of NS, (d) NC modified RAC and MWCNT modified RAC

Furthermore, the split tensile strength-compressive strength relationship for application in all three types of nano-particle modified RAC and untreated RAC was regressed based on the formula in EHE [59] and displayed as Fig.18:

$$
f_{s t}=0.257 f_{c}^{0.589}
$$


The predicted values based on the modified formula were compared with the experimental results shown in Fig.19. The predicted results matched the experimental split tensile strength quite well with average relative error of $0.62 \%$.

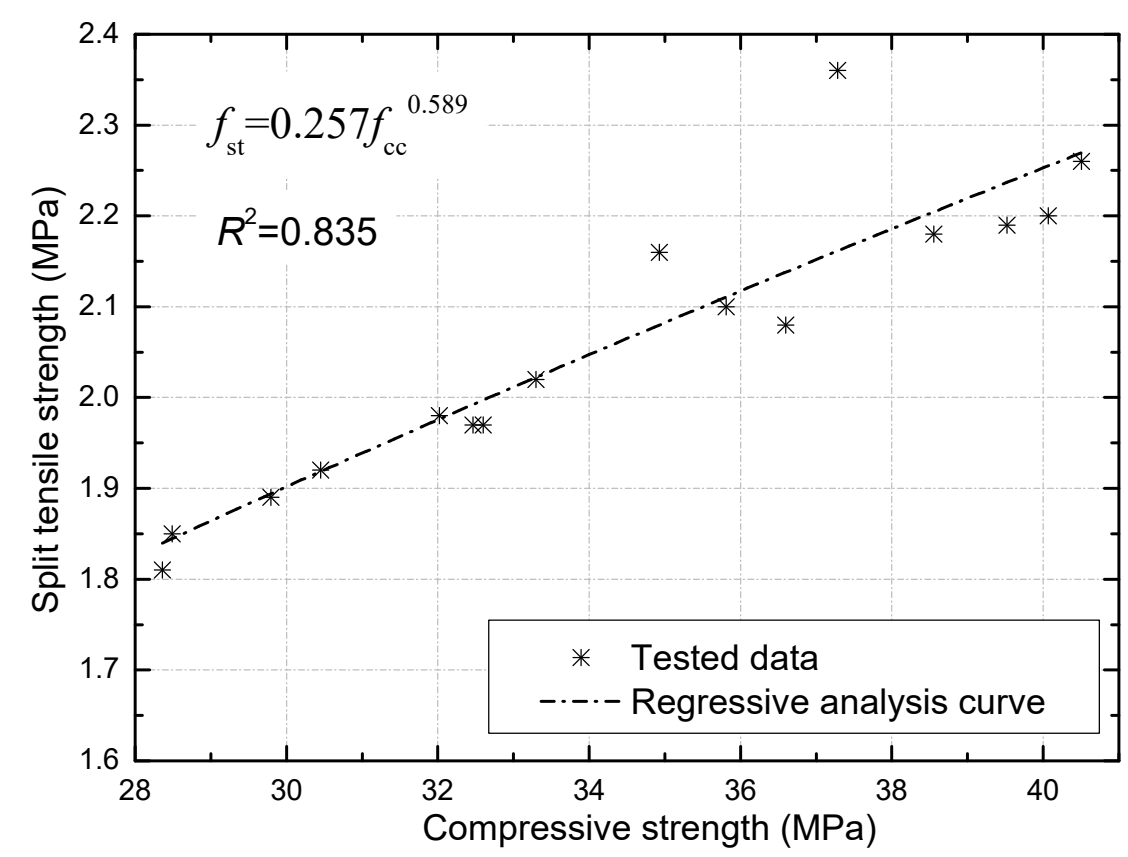

Fig. 18 Modified curves of split tensile strength

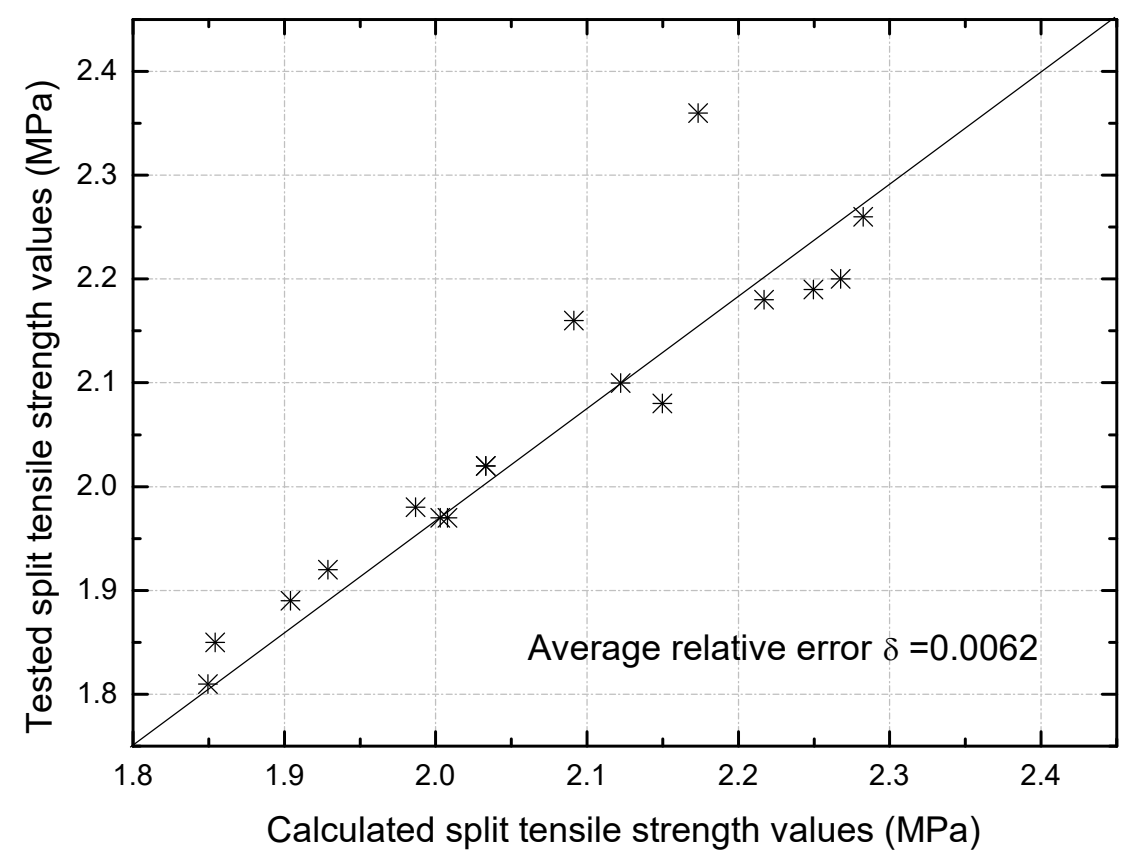

Fig.19 Comparison between test data and Eq. (2) calculated values

\section{Conclusions}

This paper investigated the mechanical properties of recycled aggregate concrete (RAC; with recycled clay brick aggregates (RCBA) as the coarse aggregates) modified by nano-particles, i.e. nano- $\mathrm{SiO}_{2}$ (NS), nano- $\mathrm{CaCO}_{3}$ (NC) and multi-wall carbon nanotubes (MWCNTs). Two experimental phases were carried out. In the first stage, nano-particle liquid with different mixing methods, i.e. surfactant and ultrasonication, were tested and analyzed by microscope 
and flexural tensile loading to identify the most effective mixing method for dispersing nano-particles in water liquid. In the second stage, experimental work was conducted to investigate the effects of replacement ratios of RAs in RAC (i.e., $0 \%, 50 \%, 70 \%$ and $100 \%$ ), type of nanoparticles (i.e. NS, NC and MWCNT), mixing methods (i.e., MI and MII,), nano-particle liquid process of ultrasonication and surfactant, dosages of nanoparticles (i.e., 1 wt.\% and 2 wt.\% of NS and 1 wt.\% and 2 wt.\% of NC, 0.1 wt.\% of MWCNT) on the workability and mechanical properties of nano-particle modified RAC specimens. The study revealed that:

1. Both the processes of surfactant and ultrasonication improved the dispersion of all the three types of nanoparticles used in this study.

2. The slump values of both untreated RAC and nano-particle modified RAC decreased with an increase of the replacement ratios of the RAs considering the porous characteristic and high water absorption of the RAs. With an increase of dosage of NS or NC, the slump decreased significantly.

3. The compressive strength of untreated RAC and nano-particle modified RAC decreased with an increase of the replacement ratios of RAs. The addition of all the three types of nanoparticles used in this study could improve the $3 \mathrm{~d}-, 7 \mathrm{~d}-$ and $28 \mathrm{~d}$-compressive strength of RAC.

4. The split tensile strength of untreated RAC and nanoparticle-modified RAC also decreased with an increase of replacement ratios of RAs, the split tensile strength of RAC incorporating NS or NC increased with an increase of dosages of NS or NC.

5. The tested split tensile strengths were compared to the predicted values from the formulas given in five different standards based on the relationship between compressive strength and split tensile strength. Besides the Spanish code [59], other codes overestimated the split tensile strength. The modified split tensile strengths-compressive strength relationship formula was regressed and evaluated.

Overall, this study confirmed that the nano-particle modified RAC is promising for structural application with desirable mechanical properties. In the future study, the effects of different experimental parameters such as wider ranges of dosages of nano-particles, surfactants of specimens, and flexural loading responses need to be evaluated.

\section{Acknowledgements}

This study is supported by National Key Research and Development Program of China (No. 2017YFC0703300) and Federal Ministry of Education and Research of Germany (Grant No.: 01DS18023). The first author gratefully appreciates the China Scholarship Council (CSC) for providing financial support to carry out the research in Purdue University.

\section{References}

[1] P. Ghisellini, X. Ji, G.Y. Liu, S. Ulgiati. Evaluating the transition towards cleaner production in the construction and demolition sector of China: A review. Journal of Cleaner Production 2018; 195: 418-434.

[2] J.L. Chen. Reconsideration of issues about construction waste recycling. Construction Technology. 2015;58-59.

[3] J.L. Chen, W.J. Zhou, W. Li. Precondition and problems in reutilization of building wastes. Architecture Technology. 2015;46(12):1114-1116.

[4] M. Etxeberria, E. Vázquez, A. Marí. Influence of amount of recycled coarse aggregates and production process on properties of recycled aggregate concrete. Cement and concrete research. 2007;37(5):735-742. 
[5] K.H. Younis, K. Pilakoutas. Strength prediction model and methods for improving recycled aggregate concrete. Construction and Building Materials. 2013;49:688-701.

[6] A. Akhtat, A. Sarmah. Strength improvement of recycled aggregate concrete through silicon rich char derived from organic waste. Journal of Cleaner Production. 2018;196: 411-423.

[7] T.U. Mohammed, A. Hasnat, M.A. Awal. Recycling of brick aggregate concrete as coarse aggregate. Journal of Materials in Civil Engineering. 2014;27(7): B4014005.

[8] J. Yang, Q. Du, Y.W. Bao. Concrete with recycled concrete aggregate and crushed clay bricks. Construction and Building Materials. 2011;25:1935-1945.

[9] C. Gao, L. Huang, L.B. Yan, B. Kasal, W.G. Li. Behavior of glass and carbon FRP tube encased recycled aggregate concrete with recycled clay brick aggregate. Composite Structures. 2016;155:245-254.

[10] B. Yan, L. Huang, L.B. Yan, C. Gao, B. Kasal. Behavior of flax FRP tube encased recycled aggregate concrete with clay brick aggregate. Construction and Building Materials. 2017;136:265-276.

[11] L. Huang, L.X. Chen, L.B. Yan, B. Kasal, Y.X. Jiang, C.Y. Liu. Behavior of polyester FRP tube encased recycled aggregate concrete with recycled clay brick aggregates: Size and slenderness ratio effects. Construction and Building Materials. 2017;154:123-136.

[12] B.J. Bolouri, K. Mahmood. Properties and performance of concrete made with recycled low-quality crushed brick. Journal of Materials in Civil Engineering. 2012;24(4):330-338.

[13] Municipality of Mashhad. Annual report of construction and demolition debris. Technical Rep. No. RTMO-85, Research Centre for Mashhad City Council, Mashhad, Iran; 2007.

[14] W.L. Jin, Z.G. Yue, L.Y. Gao. State-of-the-art development on code for design of masonry structures. Journal of Building Structures. 2010;31(6):22-28.

[15] M. Wahlstrom, Y.J. Laine, A. Maattanen, T. Luotojarvi, L. Kivekas. Environmental assurance system for use of crushed mineral demolition waste in road construction. Waste Manage. 2000;20(2):225-232.

[16] V. Nezerka, V. Hrbek, Z. Prosek, M. Somr. Micromechanical characterization and modelling of cement mortars containing waste marble power. Journal of Cleaner Production 2018;195: 1081-1090.

[17] A. Katz. Treatments for the improvement of recycled aggregate. Journal of Materials in Civil Engineering. 2004; 16(6): 597-603,

[18] C.S Poon., Z.H. Shui, L. Lam. Effect of microstructure of ITZ on compressive strength of concrete prepared with recycled aggregates. Construction and Building Materials. 2004; 18(6): 461-468.

[19] J.S. Ryu. Improvement on strength and impermeability of recycled concrete made from crushed concrete coarse aggregate. Journal of Materials Science Letters. 2002;21:1565-1567.

[20] K. H. Younis, S.M. Mustafa. Feasibility of Using Nanoparticles of $\mathrm{SiO}_{2}$ to Improve the Performance of Recycled Aggregate Concrete. Advances in Materials Science and Engineering. 2018;1512830:1-11.

[21] W.G. Li, J.Z. Xiao, Z.H. Sun, S. Kawashima, P.S. Surendra. Interfacial transition zones in recycled aggregate concrete with different mixing approaches. Construction and Building Materials. 2012;25:1045-1055.

[22] S. Erdem, A.R. Dawson, N.H. Thom. Influence of the micro- and nanoscale local mechanical properties of the interfacial transition zone on impact behavior of concrete made with different aggregates. Cement and Concrete Research. 2012;42(2):447-458.

[23] T. Akçaoğlu, M. Tokyay, T. Çelik. Assessing the ITZ micro-cracking via scanning electron microscope and its effect to the failure behaviour of concrete. Cement and 
[24] N. Otsuki, S. Miyazato, W. Yodsudjai. Influence of recycled aggregate on interfacial transition zone, strength, chloride penetration and carbonation of concrete. Journal of Materials in Civil Engineering. 2003;15(5):443-451.

[25] L. Sorelli, G. Constantinides, F.J. Ulm, F. Toutlemonde. The nano-mechanical signature of ultra high performance concrete by statistical nanoindentation techniques. Cement and Concrete Research. 2008;38(12):1447-1456.

[26] Mondal P, Shah SP, Marks LD. Nanoscale characterization of cementitious materials. ACI Materials Journal. 2008;105(2):174-179.

[27] B.M. Bibhuti, V.B. Sudhirkumar. Influence of Nano-Silica on the properties of recycled aggregate concrete. Construction and Building Materials. 2014;55:29-37.

[28] M.L. Berndt. Properties of sustainable concrete containing fly ash, slag and recycled concrete aggregate. Construction and Building Materials. 2009;23:2606-2613.

[29] F.U.A. Shaikh, S.W.M. Supit, P.K. Sarker. A study on the effect of nano silica on compressive strength of high volume fly ash mortars and concretes. Materials \& Design. 2014;60:433-442.

[30] J.S. Li, H.N. Xiao, Y. Zhou. Influence of coating recycled aggregate surface with pozzolanic powder on properties of recycled aggregate concrete. Construction and Building Materials. 2009;23(3):1287-1291.

[31] M. Sumesh, A.U. Johnson, M.Z. Jumaat, K.H. Mo, M.F. Alnahhal. Incorporation of nano-materials in cement composite and geopolymer based paste and mortar: a review. Construction and Building Materials. 2017; 148:62-84.

[32] L.G. Li, J. Zhu, Z.H. Huang, A.K.H. Kwan, L.J. Li. Combined effects of micro-silica and nano-silica on durability of mortar. Construction and Building Materials. 2017; 157:337-347.

[33] W. Li, Z. Huang, F. Cao, Z. Sun, S. P. Shah. Effects of nano-silica and nano-limestone on flowability and mechanical properties of ultra-high-performance concrete matrix. Construction and Building Materials. 2015;95:366-374.

[34] E. Mohseni, F. Naseri, R. Amjadi, M.M. Khotbehsara, M.M. Ranjbar. Microstructure and durability properties of cement mortars containing nano-TiO2 and rice husk ash. Construction and Building Materials. 2016;114:656-664.

[35] F. Sanchez, K Sobolev. Nanotechnology in concrete: a review. Construction and Building Materials. 2010:24(11):2060-2071.

[36] M. F. Islam, E. Rojas, D. M. Bergey, A. T. Johnson, A. G. Yodh. High Weight Fraction Surfactant Solubilization of Single-Wall Carbon Nanotubes in Water. Nano Letters. 2003;3(2):269-273.

[37] J.L. Luo, Z.D. Duan, H. Li. The influence of surfactants on the processing of multi walled carbon nanotubes in reinforced cement matrix composites. Physica Status Solidi A-Applications and Materials Science. 2009;206(12):2783-2790.

[38] W. Li, Z. Luo, C. Long, C. Wu, W. H. Duan, S. P. Shah. Effects of nanoparticle on the dynamic behaviors of recycled aggregate concrete under impact loading. Materials \& Design. 2016(112):58-66.

[39] P. Hosseini, A Booshehrian, and A Madari. Developing concrete recycling strategies by utilization of nano-SiO2 particles. Waste and Biomass Valorization. 2014;2(3):347-355. 
[40] H. Zhang, Y. Zhao, T. Meng, S.P. Shah. The modification effects of a nano-silica slurry on microstructure, strength, and strain development of recycled aggregate concrete applied in an enlarged structural test. Construction and Building Materials. 2015;95:721-735.

[41] K. Shiho, Jung-Woo T. S., D. Corr, Mark C. Hersam, Surendra P. Shah. Dispersion of $\mathrm{CaCO}_{3}$ nanoparticles by sonication and surfactant treatment for application in fly ash-cement systems. Materials and Structures. 2014;47:1011-1023.

[42] María del Carmen Camacho, Oscar Galao, Francisco Javier Baeza, Emilio Zornoza, Pedro Garcés. Mechanical Properties and Durability of CNT Cement Composites. Materials. 2014;7(3):1640-1651.

[43] J. Bharj. Experimental study on compressive strength of cement-CNT composite paste. Indian Journal of Pure and Applied Physics. 2015;52(1):35-38.

[44] H.K. Kima, I.S. Park, H.K.Lee. Improved piezoresistive sensitivity and stability of CNT/cement mortar composites with low water-binder ratio. Composite Structures. 2014;116:713-719.

[45] G.Y. Li, P.M. Wang, X. Zhao. Mechanical behavior and microstructure of cement composites incorporating surface-treated multi-walled carbon nanotubes. Carbon 2005;43(6): 1239-1245.

[46] M.S. Konsta-Gdoutos, Z.S. Metaxa, S.P. Shah. Multi-scale mechanical and fracture characteristics and early-age strain capacity of high performance carbon nanotube/cement nanocomposites. Cement and Concrete Composites. 2010;32(2):110-115.

[47] A. Hawreen, J.A. Bogas, A.P.S. Dias. On the mechanical and shrinkage behavior of cement mortars reinforced with carbon nanotubes. Construction and Building Materials. 2018;168:459-470.

[48] A. Tamimi, N.M. Hassan, K. Fattah, A. Talachi. Performance of cementitious materials produced by incorporating surface treated multiwall carbon nanotubes and silica fume. Construction and Building Materials. 2016;114(1):934-945.

[49] Y.J. Hwang, J.K. Lee, J.K. Lee, Y.M. Jeong, C. Seong-ir, C.A. Young, H.K. Soo. Production and dispersion stability of nanoparticles in nanofluids. Powder Technology. 2008;186(2):145-153.

[50] Y.P. Zheng, Y. Zheng, R.C. Ning. Effects of nanoparticles $\mathrm{SiO}_{2}$ on the performance of nanocomposites. Materials Letters. 2003;57(19):2940-2944.

[51] P. Bihari, M. Vippola, S. Schultes, M. Praetner, A.G. Khandoga, C.A. Reichel, C. Coester, T. Tuomi, M. Rehberg, F. Krombach. Optimized dispersion of nanoparticles for biological in vitro and in vivo studies. Particle and Fibre Toxicology. 2008;5:14.

[52] S.X. Zhou, L.M. Wu, M.N. Xiong, Q.Y. He, G.D. Chen. Dispersion and UV-VIS Properties of Nanoparticles in Coatings. Journal of Dispersion Science and Technology. 2003;25(4):417-433.

[53] J.S. Taurozzi, V.A. Hackley, M.R. Wiesner. Ultrasonic dispersion of nanoparticles for environmental, health and safety assessment-issues and recommendations. Nanotoxicology. 2011;5(4):711-729.

[54] W.G. Li, C. Long, V.V. W.Y. Tam, C.S. Poon, W.H. Duan. Effects of nano-particles on failure process and microstructural properties of recycled aggregate concrete. Construction and Building Materials. 2017;14:42-50. 
[55] W.G. Li, Z.Y. Huang, F.L. Cao, Z.H. Sun, S.P. Shah. Effects of nano-silica and nano-limestone on flowability and mechanicalproperties of ultra-high-performance concrete matrix. Construction and Building Materials. 2015;95:366-374.

[56] American Concrete Institute. ACI Committee 318: building code requirements for structural concrete. MI: Farmington Hills; 2011.

[57] GB: 50010-2002. Chinese standard: code for design of concrete structures. Beijing (China): China building press. 2002 [in Chinese].

[58] Comité Euro-International du Béton. CEB-FIP model code 1990. London: Thomas Telford. 1993.

[59] Spanish code for structural concrete EHE. Real Decreto 2661/1998, Madrid; December 11. 1998 [in Spanish].

[60] Brazilian association of technical standards NBR 6118: design of concrete structures, Rio de Janeiro. 2003 [in Portuguese]

[61] M.S. Konsta-Gdoutos, Z.S. Metaxa, S.P. Shah. Highly dispersed carbon nanotube reinforced cement based materials. Cement and Concrete Research. 2010;40:1052-1059.

[62] GB/T 50080-2002. Standard for test method of performance on ordinary fresh concrete. Standardization Administration of The People's Republic of China. 2003.

[63] A M Neville. Properties of concrete. 4th ed. New Delhi: Person Education Limited. 2006.

[64] Kadleček V 1, Modrý S, Kadleček V 1 Jr. Size effect of test specimens on tensile splitting strength of concrete: general relation. Materials and Structures. 2002;35(1):28-34. 